Check for updates

Cite this: RSC Adv., 2020, 10, 6223

Received 12th November 2019 Accepted 17th January 2020

DOI: 10.1039/c9ra09427j

rsc.li/rsc-advances

\section{The development of isoguanosine: from discovery, synthesis, and modification to supramolecular structures and potential applications}

\author{
Tingting Ding, $\uparrow$ Fan Tang, $\uparrow$ Guangcheng Ni, Jiang Liu, ${ }^{*}$ Hang Zhao (D) * \\ and Qianming Chen
}

Isoguanosine (isoG), an isomer of guanosine (G), differs from $\mathrm{G}$ by the translocation of the $\mathrm{C} 2$ carbonyl and C6 amino groups. This minor translocation of functional groups results in significant differences in the properties of $G$ and isoG. Like $G$, isoG can self-assemble into various supramolecular structures such as tetramers and decamers in the presence of various cations. And it shows a wide range of applications including in ionophores, genetics, gel formation, and cancer treatment. Although there have been many studies and reviews concerning $G$ in recent years, to the best of our knowledge, there have been no reviews that summarized isoG works. Herein, the discovery, synthesis, modification, supramolecular structures and potential applications of isoG are systematically reviewed in this article, in order to provide a reference for future studies.

\section{Introduction}

Nucleic acids are one of the most basic substances of life, not only comprising genetic material but also playing a crucial role in protein biosynthesis. Nucleic acids are biopolymers composed of nucleotide monomers. Nucleotides in living organisms are composed of a five-carbon sugar, three phosphate molecules and a nitrogenous base (adenine, guanine, cytosine, thymine or uracil, Fig. 1). Compared with the other four bases, guanine has more unique properties because of its unique 2-amino and 6-carbonyl groups. Its 2-amino and 6carbonyl groups can act as a hydrogen bond donor and receptor, respectively, resulting in its assembly into different structures, such as the cation-templated G-quartet and G-quadruplex..$^{1,2} \mathrm{G}$ quartets have various applications in ionophore and nanostructure formation. And G-quadruplexes are present in telomeres, suppressing the growth of tumors as telomerase inhibitors. They can also take part in gel formation, and recognize proteins and small molecules. In addition, Gquadruplexes are found in promoter regions of genes and in some untranslated regions of messenger RNA (mRNA).

isoG is a natural isomer of $\mathrm{G}$, differing from $\mathrm{G}$ because the C2 carbonyl and C6 amino groups are transposed (purine numbering is widely used in this paper) (Fig. 1). This minor

State Key Laboratory of Oral Diseases, National Clinical Research Center for Oral Diseases, Chinese Academy of Medical Sciences Research Unit of Oral Carcinogenesis and Management, West China Hospital of Stomatology, Sichuan University, Chengdu, Sichuan, 610041, P. R. China. E-mail: zhaohangahy@scu.edu. cn; liujiang@scu.edu.cn

$\dagger$ These authors contributed equally to this work. change leads to significant differences between isoG and $\mathrm{G}$. isoG, is also known as crotonoside, 2-hydroxyadenosine (2-OHAdo), 2-oxoadenosine (2-oxo-Ado), 1,2-dihydro-2-oxoadenosine (1,2-dihydro-2-oxo-Ado), 2-oxy-6-amino-isoguanine-D-riboside and 6-amino-9- $\beta$-D-ribofuranosyl- $9 H$ purine-2-oxo-isoguanine riboside. Significant research into isoG has been carried out since Fischer ${ }^{3}$ first synthesized isoguanine in 1897. isoG/isoguanine were firstly separated from natural substances such as croton beans (Crotonis oleum), ${ }^{4}$ butterfly wings ${ }^{5}$ and marine mollusks. ${ }^{6}$ Later, isoG and its derivatives were synthesized from three categories of methods, one is from the protected 2,6-diamino-9- $\beta$-D-ribofuranosylpurine $1,^{7}$ adenosine 1 -oxygen $2,^{8}$ the protected 6 chloroxanthosine 3 (Fig. 3$)^{9}$ by the introduction of functional groups to the base. The second is from $\mathrm{G}$ by exchanging $\mathrm{C} 2$ amino and C6 carbonyl groups, ${ }^{10}$ and the third is from 5amino-1-( $\beta$-D-ribofuranosyl)-imidazole-4-carboxamide (AICA riboside, 4, Fig. 3) to construct the nitrogen heterocycle. ${ }^{11}$ In addition, researchers have modified the sugar or base groups of isoG/isoguanine to explore differences among them and the potential unique properties. In the meantime, the structures, self-assembly properties of isoG with/without metal cations $\left(\mathrm{M}^{+}\right)$have been studied in monomer and multi-molecular layers. isoG can self-assemble into different cation-templated supramolecular structures, such as (isoG) $)_{4} \cdot \mathbf{M}^{+}$(ref. 12) and (isoG) $)_{10} \cdot \mathbf{M}^{+}{ }^{13}$ in a different manner from G. Finally, its potential applications in fields of ionophore, gel-formation, and anticancer treatments etc. are also of great significance and have been systematically reviewed. We hope that this review can not only give a glimpse of the comprehensive 
<smiles>C[C@H]1O[C@H](n2cnc3c(N)[nH]c(=O)nc32)[C@H](O)[C@@H]1O</smiles>

Isoguanosine (isoG)<smiles>Nc1nc2c(ncn2[C@@H]2O[C@H](CO)[C@@H](O)[C@H]2O)c(=O)[nH]1</smiles>

Guanosine (G)<smiles>Nc1nc2[nH]cnc2c(=O)[nH]1</smiles>

Guanine<smiles>Nc1ncnc2[nH]cnc12</smiles>

Adenine<smiles>Cc1c[nH]c(=O)[nH]c1=O</smiles>

Thymine<smiles>Nc1cc[nH]c(=O)n1</smiles>

Cytosine<smiles>O=c1cc[nH]c(=O)[nH]1</smiles>

Uracil

Fig. 1 Structures of iso $G$ and $G$ as well as the five natural bases.

development surrounding isoG, but also inspire further research into this fascinating topic.

\section{Discovery process of isoG}

In 1897, Fischer ${ }^{3}$ synthesized many purines and identified a strong similarity between guanine and one particular product 2-oxo-6-aminopurine, which had not been discovered in nature (Fig. 2). Believing that 2-oxo-6-aminopurine was oxidized adenine, he suggested that 2-oxo-6-aminopurine would most likely be discovered in animals. And 2-oxo-6-aminopurine may have already been mistaken for guanine. Then in 1927, Buell ${ }^{14}$ et al. found that oxyadenine, a purine isolated from pig blood, is consistent with 2-oxo-6-aminopurine. However, the presence of 2-oxo-6-aminopurine in pig blood could not be confirmed. In 1932, during a study of croton seeds, Cherbuliez and Bernhard ${ }^{4}$ accidently discovered a new glucoside, which had not been discovered in nature. They identified it as 2-hydroxy-6-aminopurine-D-riboside. However, the yields obtained from the seeds were variable and very low, and glycosyl crystals could not be obtained by hydrolysis. Subsequently, in 1935, $\operatorname{Spies}^{15}$ et al. successfully enriched the new glucoside and obtained the crystals, and identified the structure as the D-ribose form. In 1939, Spies ${ }^{16}$ confirmed the observations of Fischer ${ }^{3}$ and Cherbuliez $^{4}$ et al. that isoguanine is converted to xanthine by hydrochloric acid but is resistant to nitric acid, whereas guanine is converted to xanthine in nitric acid. This reactivity was evidence of the 2-oxo-6-aminopurine structure that Bendich had observed, i.e., that 2,6-diaminopurine can only be converted to isoguanine rather than xanthine in the reaction with excess nitrous acid. In 1939, Falconer ${ }^{17}$ et al. confirmed the ribose was linked to the base at N9 position. Afterwards, isoguanine was separated from the butterfly wings of Prioneris thestylis by Purrmann $^{5}$ in 1940 and by Pettit ${ }^{18}$ et al. in 1976. In 1951,

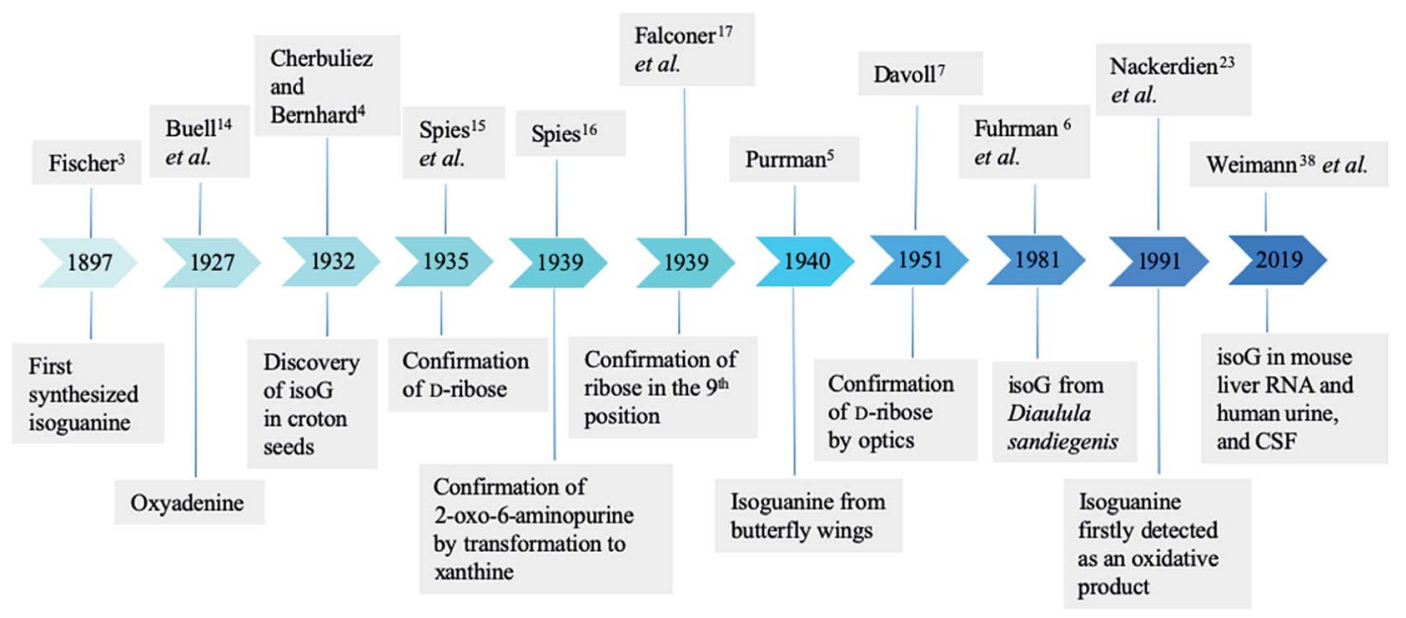

Fig. 2 Natural discovery of isoguanine/isoG and the confirmation of structure. 
experiments by Davoll ${ }^{7,19}$ et al. into optical properties of these compounds revealed that isoG was consistent with 9- $\beta$-D-ribofuranosylisoguanine. Later, in a study of Diaulula sandiegensis in 1981, Fuhrman ${ }^{6}$ et al. confirmed the presence of isoG in extracts of the digestive glands of the sea slug Diaulula sandiegensis. However, the yield was very low, only one milligram of crystals can be obtained from per gram of dry tissue.

Interestingly, although isoG is a nucleoside that has been isolated from a variety of species, it does not exist as a natural nucleic acid. In 1950, Brown ${ }^{20}$ et al. demonstrated that isoguanine is not a precursor of nucleoside biosynthesis in mice. In 1952, they reported that isoguanine could not be used as a pure source of purines in Lactobacillus casei, nor could it be integrated into nucleic acid. ${ }^{2 \mathbf{1}}$ Notably, $\mathrm{C}^{\mathbf{1 4}}$ crotonoside has been used to investigate its role in the metabolism of Escherichia coli (E. coli). The results indicate that isoguanine and its derivatives play an important role in nucleic acid metabolism. ${ }^{21,22}$

In 1991, using gas chromatography/mass spectrometry (GCMS) in isolated human chromatin isoguanine, Nackerdien ${ }^{23}$ et al. firstly detected 2-OH-Ade within $\mathrm{Ni}$ (II)/Co(II)- $\mathrm{H}_{2} \mathrm{O}_{2}$-treated DNA. And in 1992, Dizdaroglu ${ }^{24}$ reported that in the presence of $\mathrm{Fe}(\mathrm{III}), \mathrm{Cu}(\mathrm{II}), \mathrm{Ni}(\mathrm{II})$ and $\mathrm{Co}(\mathrm{II})$, isoguanine (2-hydroxyadenine) was a product of $\mathrm{H}_{2} \mathrm{O}_{2}$-treated mammalian chromatin both in vivo and in vitro. Oxidation reaction commonly occurs in cells because of the presence of reactive oxygen species (ROS), which plays an important role in DNA damage. In this respect, it is logical that isoguanine is more abundant in human cancerous tissue than in normal tissue, which is reported by Olinski ${ }^{\mathbf{2 5 , 2 6}}$ et al. in 1992 and 1994. In 1993, Dizdaroglu ${ }^{27}$ et al. identified isoguanine in mice at levels of only a few oxidation sites per $10^{5}$ DNA bases. They also identified isoguanine as an oxidation product of hepatic chromatin exposed to $\gamma$-ray in pregnant rats and fetuses of theirs. In 1996, using GC-MS, Jaruga ${ }^{28}$ et al. reported that isoguanine is produced as a DNA oxidation product of adenine in $E$. coli, as well as in cultured human lymphoblast cells. These have drawn attention toward isoguanine as a marker for oxidative damage formation, repair, mutagenicity. ${ }^{29-34}$

In 2002 , Cadet $^{35}$ et al. demonstrated that after $\gamma$-ray radiolysis and Fenton reaction of free nucleosides, the yield of $2^{\prime}$ deoxyisoguanosine (isoG ${ }_{\mathrm{d}}$ ) was low, compared to the yield of 8oxo-2'-deoxy-adenosine, expect in the presence of ferrous ion $\left(\mathrm{Fe}^{2+}\right) /$ ethylenediaminetetraacetic acid (EDTA) with oxygen or cuprous ion $\left(\mathrm{Cu}^{+}\right)$. However, $\mathrm{Fe}^{2+} /$ EDTA with oxygen or $\mathrm{Cu}^{+}$are typically at very different conditions from those found in cells. They concluded that isoG $\mathrm{G}_{\mathrm{d}}$ cannot be detected under a limit of per $10^{7}$ bases in human DNA and E. coli. They also reported that the process of conventional GC-MS, which involves acid hydrolysis and derivation at high temperature, may have caused an overestimation of isoguanine/isoG..$^{35-37}$ Notably, in 2019, using the ultra-performance liquid chromatography (UPLC) and electrospray ionization isotope dilution tandem mass spectrometry, Weimann ${ }^{38}$ et al. firstly identified and quantified the ribonucleoside isoG in mouse liver RNA, human urine, and cerebrospinal fluid (CSF). However, the amount of detected isoG is more than or equal to that of 8-oxo-G, which is most easily oxidized, and iso $\mathrm{G}_{\mathrm{d}}$ was not detected. These data are opposed to the common hypothesis that the free nucleoside isoG may originate from oxidation reaction. As a result, the reason why isoG exists in mammals still remains a matter of study.

\section{Syntheses of isoG}

As a special nucleoside, isoG is expected to present applications in various areas. However, its yield from natural sources is too low. Thus, many synthetic methods have been reported (Table 1), and these synthetic methods can be divided into three categories: (1) the introduction of the functional groups to existing heterocyclic 9- $\beta$-D-ribofuranosylpurine nucleosides

Table 1 Syntheses of isoguanine/isoG are divided into three categories: (1) the introduction of functional groups to the existing heterocycle, (2) $G$ as a initial reactant to isoG by exchanging C2 amino and C6 carbonyl groups, (3) construction of a nitrogen heterocycle with AICA

\begin{tabular}{|c|c|c|c|c|}
\hline Year & Authors & Initial substrates & Productivity & References \\
\hline 1897 & Fischer & 6-Oxy-2,8-dichlorpurine & $-^{a}$ & 3 \\
\hline 1951 & Davoll & $\begin{array}{l}\text { 2,6-Diamino-9- } \beta \text {-D-glucopyranosylpurine/ } \\
2,6 \text {-diamino-9- } \beta \text {-D-ribofuranosyl purine }\end{array}$ & $\begin{array}{l}55 \% \text { 9- } \beta \text {-D-Glucopyranosylisoguanine/ } \\
57 \% \text { 9- } \beta \text {-D ribofuranosylisoguanine }\end{array}$ & 7 \\
\hline 1964 & Brown et al. & Adenosine 1-oxide & Variable & 8 \\
\hline 1965 & Ravindranathan et al. & 2,6-Diaminopurine riboside & $-^{a}$ & 40 \\
\hline 1968 & Montgomery et al. & The protected 2,6-diaminopurine nucleoside & By-product & 42 \\
\hline 1995 & Napoli et al. & The protected 6-chloroxanthosine & $20 \%$ isoG & 43 \\
\hline 1995 & Napoli et al. & $2^{\prime}, 3^{\prime}, 5^{\prime}$-tri- $O$-acetylxanthosine & $76 \%$ isoG & 43 \\
\hline 1997 & Napoli et al. & The protected 6-chloroxanthosine & $80 \%$ isoG & 48 \\
\hline 2012 & Cheng et al. & Adenine & $-^{a}$ & 44 \\
\hline 1985 & Nair et al. & G & $34 \%$ isoG & 39 \\
\hline 1991 & Divakar et al. & G & $64 \%$ isoG & 10 \\
\hline 1968 & Yamazaki et al. & 4-Amino-5-imidazole carbonitrile (AICN) & $-^{a}$ & 45 \\
\hline 1976 & Yamazaki et al. & AICA (riboside) & By-product & 46 \\
\hline 1987 & Reese et al. & The protected AICA riboside & $-{ }^{a}$ & 9 \\
\hline 1987 & Chern et al. & AICA (riboside) & $77 \%$ isoG $/\left(-^{a}\right)$ isoguanine & 11 \\
\hline
\end{tabular}

${ }^{a}$ The yield is not mentioned. 


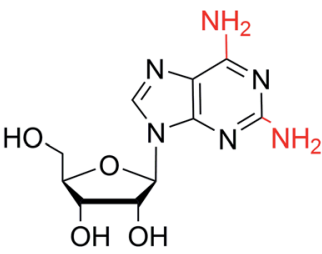

1

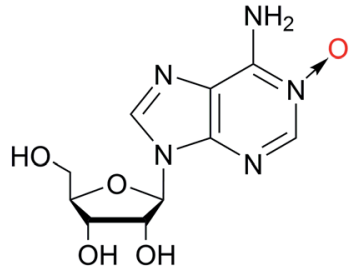

2

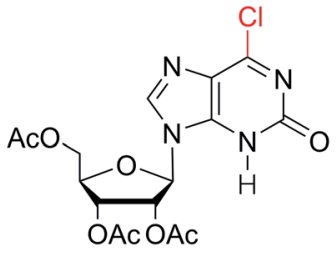

3

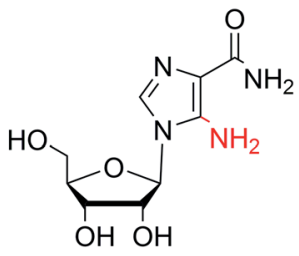

4

Fig. 3 Common substrates for the synthesis of isoG.

(Fig. 3), such as 2,6-diamino-9- $\beta$-D-ribofuranosylpurine $1{ }^{7}$ adenosine 1-oxide $2,{ }^{8}$ the protected 6-chloroxanthosine $3,{ }^{39}(2) \mathrm{G}$ as an initial reactant to build isoG by exchanging the $\mathrm{C} 2$ amino and C6 carbonyl groups, (3) the construction of nitrogen heterocycle with AICA riboside (4, Fig. 3 ) as a precursor for base synthesis to introduce oxo group at $\mathrm{C} 2$ position. Notably, the third method is challenging because it is difficult to obtain AICA. These syntheses will be discussed in detail in the following parts.

\subsection{Introducing functional groups on the existing heterocycle}

Isoguanine was initially synthesized by Fischer ${ }^{3}$ in 1897. It can resist the deamination by nitrous acid, and the reaction of 2,6diaminopurine with excess nitrous acid only yields isoguanine not xanthine. In 1951, Davoll, ${ }^{79}$ et al. reported that 9- $\beta$-Dglucopyranosyl-isoguanine can be obtained in $55 \%$ yield by the reaction of 2,6-diamino-9- $\beta$-D-glucopyranosylpurine with nitrous acid, while 9- $\beta$-D-ribofuranosyl-isoguanine can be obtained in $57 \%$ yield from the reaction of 2,6 -diamino-9- $\beta$-Dribofuranosylpurine (1, Fig. 3) and nitrous acid (Fig. 4). However, the overall yields are low and harmful heavy metal ions $\left(\mathrm{Hg}\right.$ and $\mathrm{Pb}$ ) are used. So in 1965, Ravindranathan ${ }^{40}$ et al. synthesized isoG using the way of Davoll but using much charcoal instead of a lead salt for purification. On account of the relevance of ultraviolet (UV) light and the mutations in nucleic acids, in 1964, Brown ${ }^{8}$ et al. reported a photochemical preparation of isoG from adenosine 1-oxide (2, Fig. 4). Adenosine 1-oxide is more sensitive to UV light than adenosine. However, this method gives variable proportions of two major products. One product is adenosine (6, Fig. 4) via the direct loss of oxygen. The other product is isoG via the rearrangement of oxygen atom to the neighboring carbon atom. Subsequently in 1975, Mantsch ${ }^{41}$ et al. concluded that if nucleotides of the initial substance 2 is irradiated with UV light under alkaline condition (0.01 $\left.\mathrm{M} \mathrm{NH}_{4} \mathrm{OH}\right)$, isoG nucleotides can be the corresponding primary products. This is also the case for adenine 1-oxide (10, Fig. 5). ${ }^{8}$

In 1968, in a synthesis of 2-fluoroadenosine by Montgomery ${ }^{42}$ et al., isoG was reported to be a by-product, relying on a protected 2,6-diaminopurine nucleoside (5, Fig. 4). Generally, the introduction of $\mathrm{N}$ to the assigned activated nucleoside bases of guanine, cytosine and adenine is easy but this is not the case for isoG. A significant intermediate 3 can be obtained from $2^{\prime} 3^{\prime} 5^{\prime}$-tri-O-acetylxanthosine 7 (Fig. 4). Nevertheless, in 1995, Napoli $^{43}$ et al. reported a direct route from the protected 6chloroxanthosine 3 to isoG, but this gives a very low yield of $20 \%$. So, they synthesized isoG through the reagent to nucleophilic attack on the pyridinium $\alpha$-carbon, and obtained the intermediate (8, Fig. 4). Then isoG was isolated by HPLC in $76 \%$ overall yield by ring opening (Zincke reaction) of the compound 8. Then in 1997, they proposed another way by introducing a strong electron-withdrawing group in the heterocyclic to enhance the reactivity of $\mathrm{C} 6$ towards aqueous ammonia, in

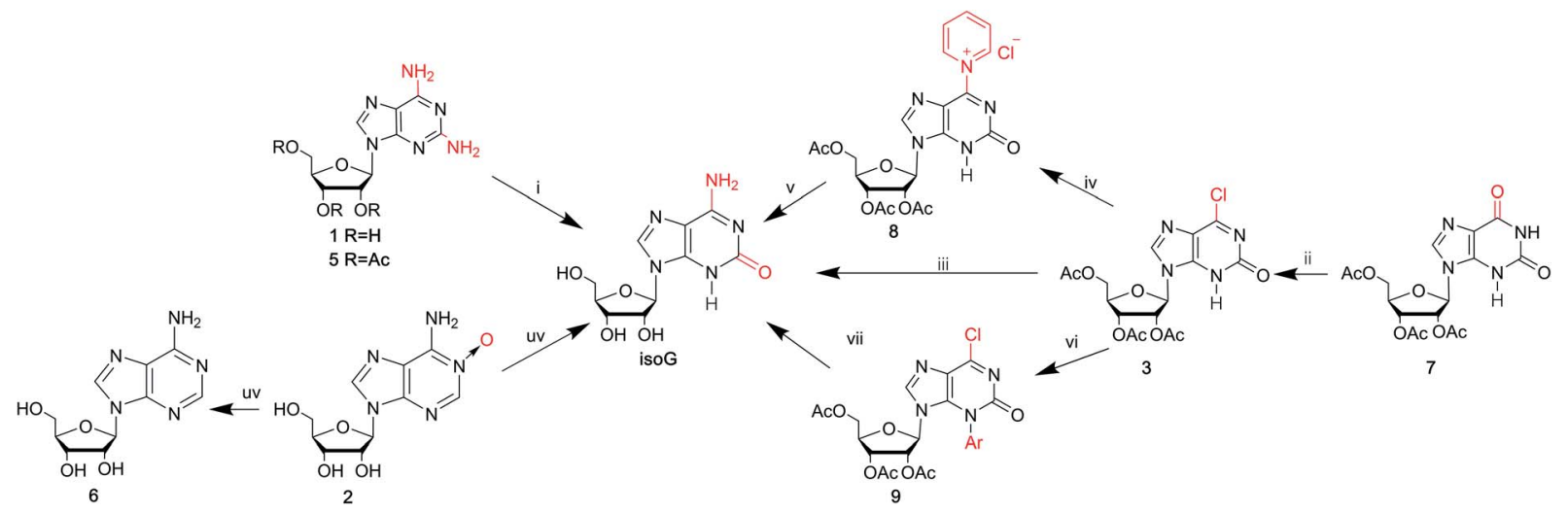

Fig. 4 Syntheses of isoG via introducing functional groups. (i) Nitrous acid for compound 1; hydrogen and palladium-on-charcoal catalyst, $40 \%$ fluoroboric acid, sodium nitrite for compound 5; (ii) $\mathrm{PPh}_{3}$ (2 mol equiv.), $\mathrm{CCl}_{4}, 3 \mathrm{~h}$, reflux; (iii) aq. $\mathrm{NH}_{3}$ (32\%), 3 days, room temperature; (iv) pyridine-water (1:1), $2 \mathrm{~h}, 50^{\circ} \mathrm{C}$; (v) aq. $\mathrm{NH}_{3}(32 \%), 5 \mathrm{~h}, 50{ }^{\circ} \mathrm{C}$; (vi) 2,4-dinitrochlorobenzene in DMF solution, $1.5 \mathrm{~h}, 80{ }^{\circ} \mathrm{C}$; (vii) $\mathrm{NH}_{4} \mathrm{OH}$. 


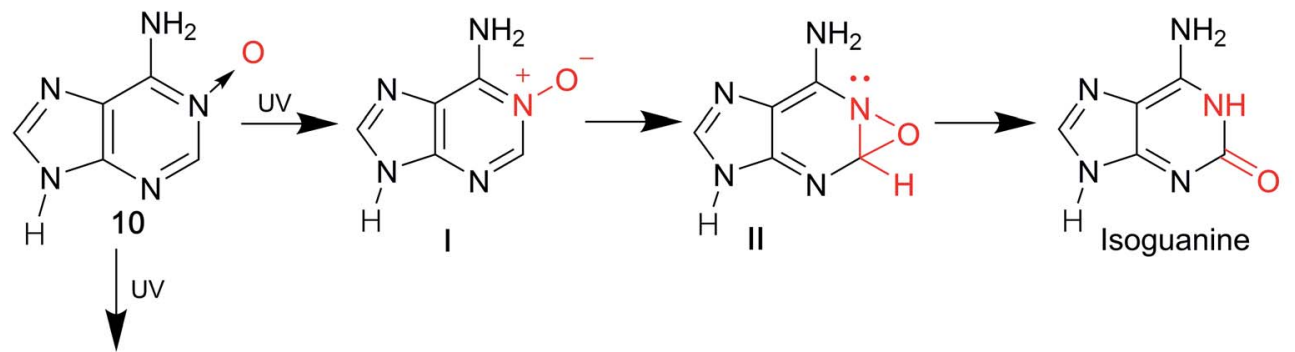

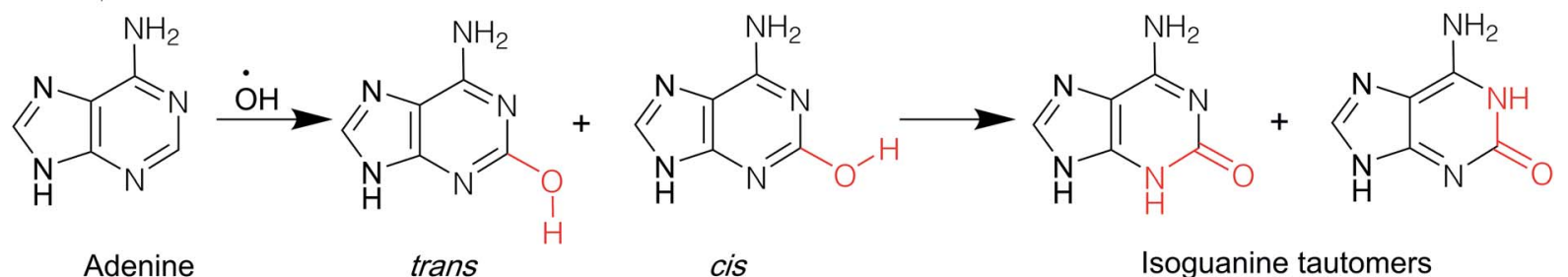

Fig. 5 Syntheses of isoguanine via introducing functional groups.

a yield of $80 \%$, with an important intermediate (9, Fig. 4). In 2012, Cheng ${ }^{44}$ et al. published a new two-step method based on adenine. A mixture of isoguanine tautomers was obtained (Fig. 5). Reactions had been proved where $\mathrm{OH}$ radicals attack adenine on the $\mathrm{C} 2, \mathrm{C} 4, \mathrm{C} 5$, and $\mathrm{C} 8$ positions, and the reactions are spontaneous and exothermic. In the first step, attack by $\mathrm{OH}$ radicals at the $\mathrm{C} 2$ position of adenine forms a favorable lowenergy complex (Fig. 5). In the second step, the enol cis-trans forms are converted into the corresponding $\mathrm{N} 1 \mathrm{H} / \mathrm{N} 3 \mathrm{H}$ keto forms.

\subsection{G to isoG by exchanging $\mathrm{C} 2$ amino and $\mathrm{C} 6$ carbonyl groups}

As mentioned above, the route from 2,6-diaminopurines to isoG requires harmful heavy metal ions $(\mathrm{Hg}$ and $\mathrm{Pb})$ and the overall yields are low. isoG was reported as a by-product in a synthesis of nucleosides from 2,6-diaminopurines, as well as from adenosine-1-oxide, both in variable yields. In 1985, Nair ${ }^{39}$ et al. found a new reproducible and efficient method for the synthesis of isoG starting from G (Fig. 6). This method contains five steps. Firstly, the sugar is protected by selective acetylation. Secondly, reaction with phosphorus oxychloride and $N, N$-dimethylaniline yields the 6-chloropurine nucleoside (11, Fig. 6). Thirdly, $n$ pentyl nitrite reacts with diiodomethane to obtain protected 2iodo-6-chloropurine nucleoside (12, Fig. 6). Then, 2-iodoadenine (13, Fig. 6) is obtained by reacting with ethanolic ammonia. And finally, in the last key step in this process, photoinduced hydration occurs. The product isoG was isolated by HPLC. However, this method gives a low yield about $34 \%$. In addition, in the fifth step, the requirement of UV irradiation limits the spread of this synthetic route. Therefore, in 1991, Divakar $^{\mathbf{1 0}}$ et al. developed an improved five-step route (Fig. 6) starting from $\mathrm{G}$, which achieved isoG with a $64 \%$ overall yield involving the same 6-chloropurine nucleoside (11, Fig. 6), with an important intermediate 14. This means that, for the latter reaction, inavailability of direct synthesis to 6-chloroxanthosine is not required. In contrast, a better yield is obtained. Moreover, conditional complex photochemical steps are avoided.

\section{3 isoG from AICA by constructing a nitrogen heterocycle}

In 1968, Yamazaki ${ }^{45}$ et al. found that isoG/isoguanine can be obtained from 4-amino-5-imidazole carbonitrile (AICN, 16, Fig. 7) and its protected riboside (21, Fig. 7), but the yield is too low. For a long time, there have been great efforts to synthesize

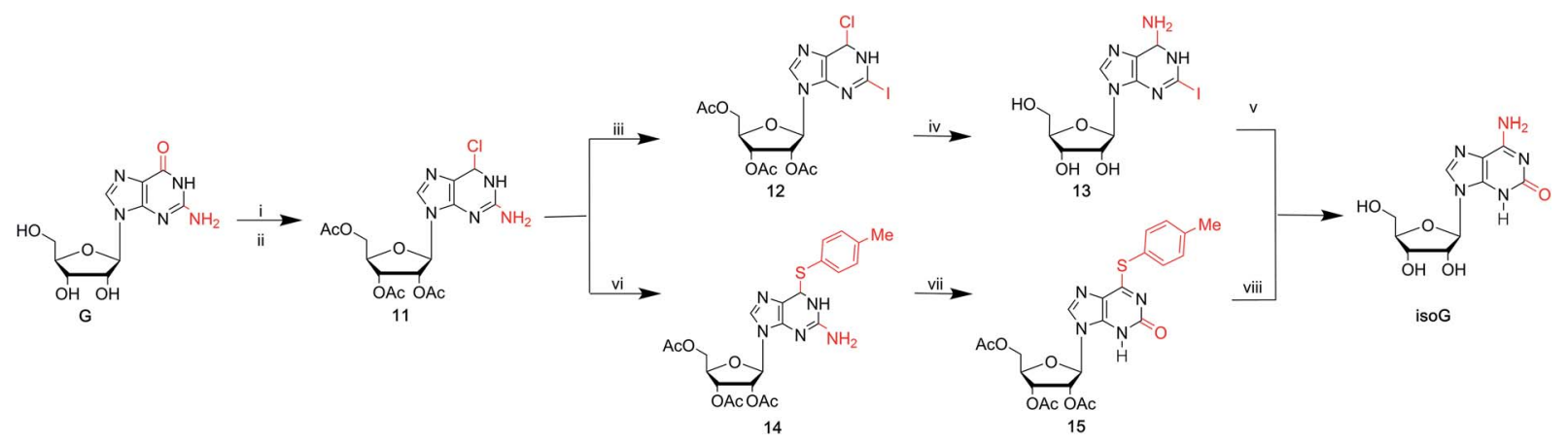

Fig. 6 Syntheses of isoG from G. (i) $\mathrm{Ac}_{2} \mathrm{O}$, pyridine, $\mathrm{DMF}, 70^{\circ} \mathrm{C}$; (ii) $\mathrm{POCl}_{3}, \mathrm{~N}, \mathrm{~N}$-dimethylaniline, $\mathrm{CH}_{3} \mathrm{CN}, 100^{\circ} \mathrm{C}$; (iii) $n-\mathrm{C}_{5} \mathrm{H}_{11} \mathrm{ONO}, \mathrm{CH}_{2} \mathrm{I}_{2}, \mathrm{heating}$; (iv) $\mathrm{NH}_{3}, \mathrm{C}_{2} \mathrm{H}_{5} \mathrm{OH}$; (v) $\mathrm{H}_{2} \mathrm{O}$, UV; (vi) toluerthliol, TEA, DMF, $100{ }^{\circ} \mathrm{C}$; (vii) $50 \% \mathrm{AcOH}, \mathrm{NaNO}_{2}, 50{ }^{\circ} \mathrm{C}$; (viii) ammonia, ethanol, $70{ }^{\circ} \mathrm{C}$. 

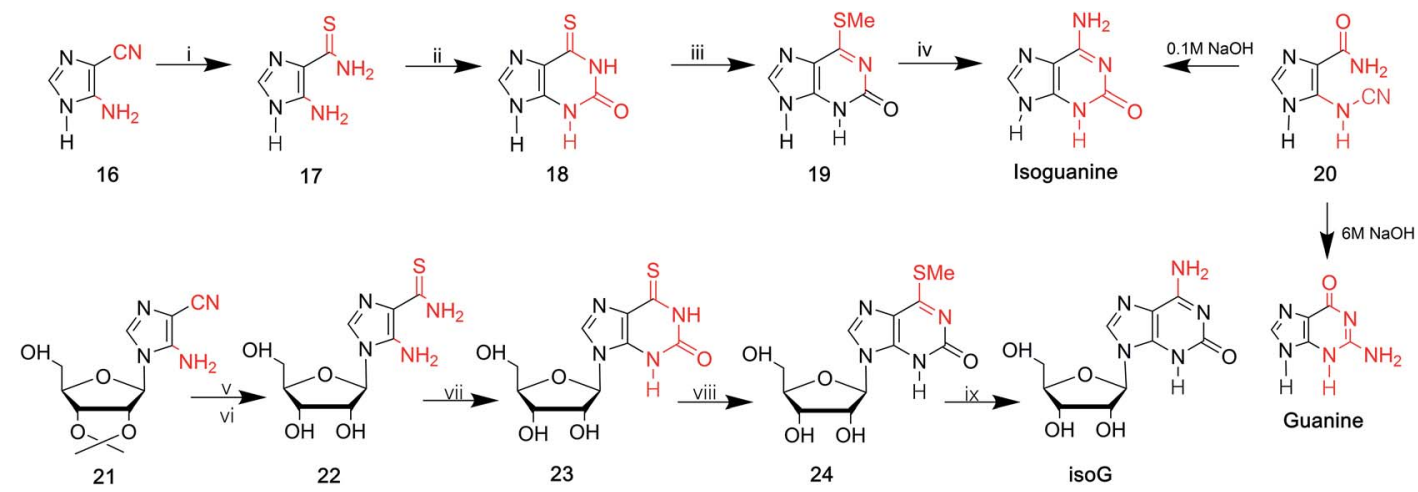

Fig. 7 Syntheses of isoG/isoguanine from $\mathrm{AICN}$. (i) $\mathrm{H}_{2} \mathrm{~S}, \mathrm{KOH}$; (ii) fusion with urea; (iii) $\mathrm{CH}_{3}$ l, alkaline solution; (iv) ammonia, autoclave at $130{ }^{\circ} \mathrm{C}$, 3 h; (v) $\mathrm{H}_{2} \mathrm{~S}$; (vi) acid condition, hydrolyzation; (vii) diethyl carbonate; (viii) $\mathrm{CH}_{3}$ l; (ix) ammonia.

guanine from AICA. In 1976, isoguanine was discovered as an unexpected product in a synthetic process of guanine by Yamazaki $^{46}$ et al. from AICA. Isoguanine was obtained from an intermediate substance 4-cyanamido-imidazole-carboxamide (20, Fig. 7) in weakly alkaline or neutral conditions. Whereas in alkaline conditions, the compound $\mathbf{2 0}$ was converted into guanine. They synthesized isoG depending on the protected AICA riboside (25, Fig. 8), in low yield with three plausible and non-isolated intermediates $(\mathbf{2 7}, \mathbf{2 8}, \mathbf{3 0}$, Fig. 8). Subsequently in 1987, Reese ${ }^{9}$ et al. reported that the compound 30 can also be obtained from compound $\mathbf{2 5}$ via the intermediate putative methoxyacetyl thioureido derivative 29 (Fig. 8). Moreover, in 1987, enlightened by a synthesis of 1-methyl-isoG, Chern ${ }^{\mathbf{1 1}}$ et al. proposed that an $N, N^{\prime}$-dicyclohexylcarbodiimide (DCC)mediated cyclodesulfurative method would allow milder reaction conditions and produce a higher yield of isoG. They reported an improved, more efficient route in milder reaction conditions using AICA 32 and its riboside 4 to synthesize isoguanine and isoG, respectively (Fig. 9). When AICA/AICA riboside $\mathbf{3 2} / \mathbf{4}$ reacts with benzoyl isothiocyanate in dimethylformamide (DMF) at room temperature, it can be converted to benzoylthiourea intermediates 33/34, respectively. Next, DCC was added to this system and isoguanine/isoG can be obtained via stirring, washing and separation. And isoG can be obtained in a high overall yield of $77 \%$. In 1991, they also synthesized several 1-substituted isoG through similar DCCmediated ring-closure reactions. ${ }^{47}$

In summary, as shown in Table 1, over time, the syntheses of isoG/isoguanine have developed toward milder reaction conditions and higher yield. To date, the most outstanding synthetic route to isoG is that involving 6-chloroxanthosine by $\mathrm{Napoli}^{\mathbf{4 8}}$ et al., with a yield of $80 \%$, under mild conditions.

\section{The modified isoG}

In the above sections, we have discussed the discovery of natural isoG, as well as a variety of synthetic methods. isoG contains a nitrogenous base (a purine ring) and a carbohydrate residue. Minor modification to the base or sugar may lead to great differences in the higher structures and properties compared to the parent compound. Thus, a number of base-
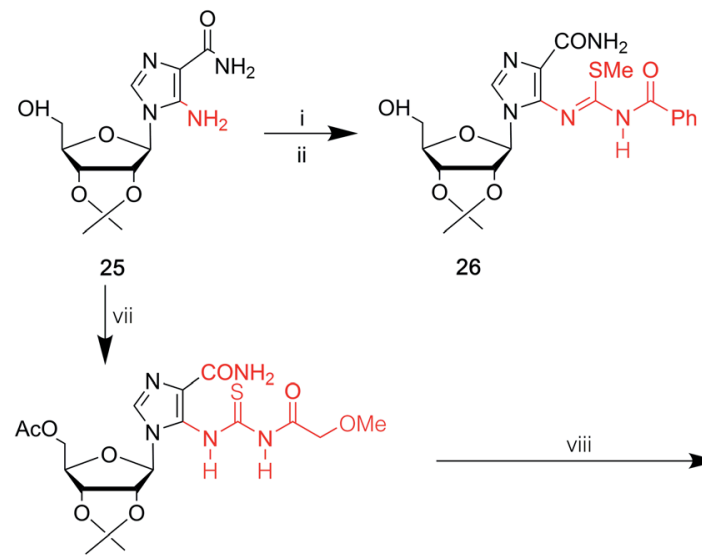

29

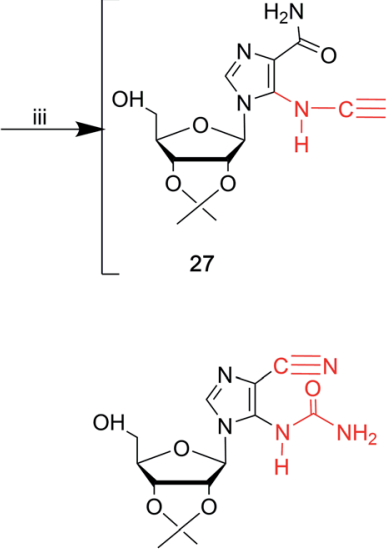

30

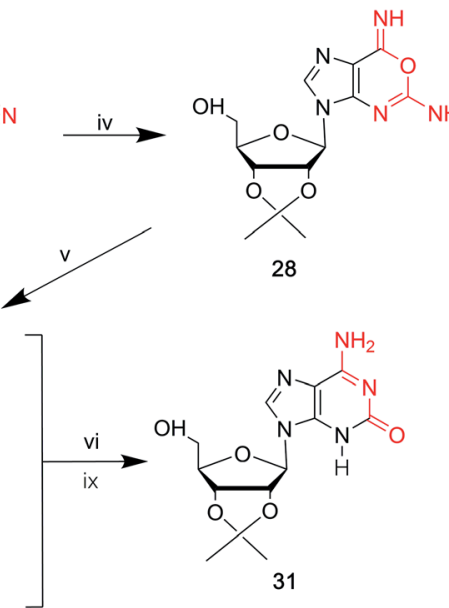

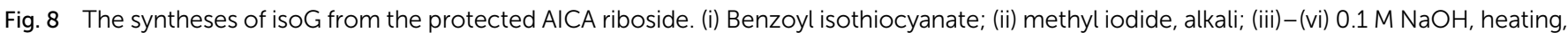

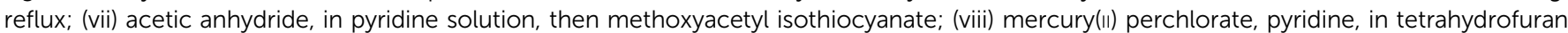
solution, room temperature, then methanolic ammonia; (ix) $N^{1}, N^{1}, N^{3}, N^{3}$-tetramethylguanidine, water, in tetrahydrofuran, room temperature. 


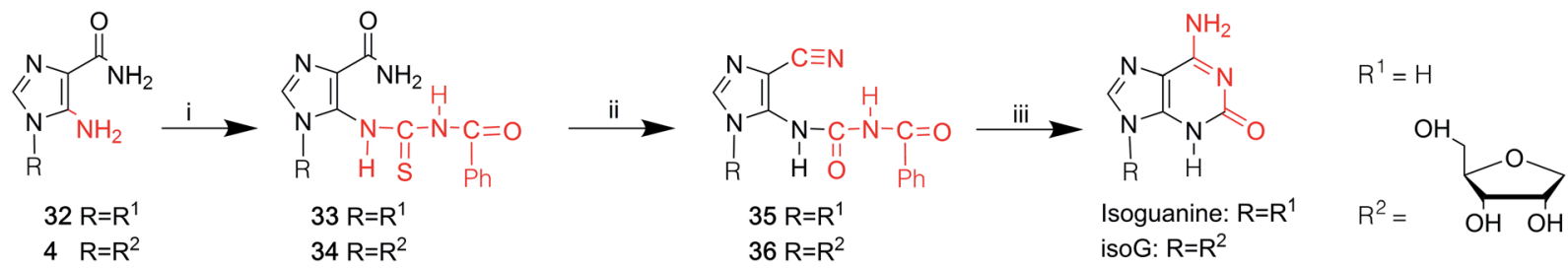

Fig. 9 Syntheses of isoguanine/isoG from AICA and its riboside. (i) Benzoyl isothiocyanate, DMF, room temperature; (ii) dicyclohexylcarbodiimide, DMF, room temperature; vacuo, $50{ }^{\circ} \mathrm{C}$, hot toluene; (iii) ethanol, $33 \%$ aqueous ammonia.

modified (Fig. 10) or sugar-modified (Fig. 11) analogs of isoG have been discovered in nature or synthesized. Summaries are shown in Table 2. And some of their properties are discussed in the following part.

\subsection{Base-modified isoG}

4.1.1 1-Methyl-isoG (doridosine). Dorid nudibranchs are shellless sea slugs. Interestingly, they have long lives despite lacking the typical protection given by a shell. Thus, there has been significant conjecture about their defense mechanism. In 1979, a tissue analysis by Fuhrman ${ }^{49}$ et al. revealed that only the digestive gland extract is toxic, and this acts as the unique defense mechanism of Dorid nudibranch. In 1980, Quinn ${ }^{50}$ et al. isolated a new pharmacologically active substance from the Australian sponge Tedania digitate, in a yield of $0.71 \%$ from the crude extract. They also developed a synthesis of doridosine from AICA riboside (4, Fig. 3) by acetylation in four steps, giving a yield of $39 \%$. Meanwhile, they identified doridosine as identical to 1-methyl-isoG (37, Fig. 10) by spectrum, chemical degradation, synthetic analysis. In 1981, Fuhrman ${ }^{51}$ et al. concluded that the substances isolated from nudibranch and sponge are indeed the same. Moreover, 1-methyl-isoG 37 has been shown to have several pharmacological effects related to hypotension, hypothermia and anti-inflammatory, and these will be discussed in Section 6.3 .

4.1.2 2-Methoxyadenine (spongosine). Nucleosides from marine organism have been found to have various biological activities, and this has aroused great interests among scholars. In a study of Carribean sponge Cryptotethya crypta in Florida, ${ }^{52,53}$ a mixture of two unnatural nucleosides spongothymidine and spongouridine were obtained. And these were identified as 3 - $\beta$-arabofuranosides of thymidine and uridine, respectively. The development of materials has promoted elucidation of the composition and structures of these purines and the carbohydrate. Then in 1951, Bergmann ${ }^{53}$ et al. firstly isolated spongosine (38a, Fig. 10) from Cryptotethya crypta. It was indentified as pentosylmethyl-aminooxypurine. In 1956, they determined the structure of D-riboside of 2-methoxy-6aminopurine (2-methoxyadenine) using UV absorption spectra and the synthesis of 2-methyladenine. ${ }^{54}$ They concluded that it is not only the first methoxy purine found in nature, but also the first occurrence of methoxy substance isolated from animals. In addition, in 1994, Searle ${ }^{55}$ et al. firstly identified $2^{\prime}$-deoxyspongosine [9 $\beta$ - $\left(2^{\prime}\right.$-deoxy-D-ribofuranosyl)-2-methoxyadenine, 38b, Fig. 10] as a natural product from Western Australia.

4.1.3 More analogs. In terms of the great effects of 1-methylisoG 37, many analogs of 1-methyl-isoG have been prepared from the protected imidazole nucleoside to explore the structure-activity correlation. As shown in Fig. 10, some N1substituted isoG 39 have been developed to explore the importance of N1-methyl-substituted compounds in marine products. Some of these have been synthesized in good yield, by Bartlett ${ }^{56}$ et al. in 1981 and Chern ${ }^{47}$ et al. in 1991. In addition, in 1981, using 1-methyl-isoG 37 as a starting material, C8-substituted-1methyl-isoG 40 was prepared by Bartlett ${ }^{56}$ et al. Their effects on cardiovascular response and muscle relaxation, etc. will be discussed later in Section 6.3. Moreover, in 2017, Thomas $^{57}$ et al. identified 8-oxo-1-methyl-isog 41a and 3'-O-acetyl-8-oxo-1methyl-isog 41b as natural derivatives of isoG in a sponge from the Northeastern Atlantic, Clathria (Microciona) strepsitoxa. And these compounds showed no significant cytotoxic or antimicrobial activity. In addition, in $1994, \mathrm{Lee}^{58}$ et al. synthesized a series of 6-substituted isoG derivatives $\mathbf{4 2}$ and isoG by one-step nucleophilic substitution from the compound $\mathbf{1 5}$ (Fig. 6). These were synthesized to explore the antitumor activities, and the results will be discussed later in Section 6.3.

8-Aza-7-deazapurines and their 7-halogenated derivatives have been reported to possess excellent biological and physical properties, such as antiparasitic and antiviral effects, because of their structural similarity to purines in nucleic acids. And earlier studies showed that 7-substituents of 8-aza-7deazapurine nucleosides and 7-deazapurine nucleosides incorporated oligodeoxynucleosides could increase antiparallel strand (aps) duplexes stability. ${ }^{59-66}$ Thus, in 2003 and 2007, Seela ${ }^{67,68}$ et al. synthesized 7-halogenated 8-aza-7deazaisoguanosine derivatives $\mathbf{4 3}$ and 7-halogenated 7-deazaisoguanosine derivatives $\mathbf{4 4}$ from 8-aza-7-deazapurine-4,6diamine riboside derivatives. Their tautomerism will be discussed later in Section 5.1. Moreover, in 2004, 8-aza-3-deazaisoG 45 was synthesized by Jeselnik ${ }^{69}$ et al. to study the influence of the lack of $N 3$ on the hydrogen-bonding modes. 8-Azapurine nucleosides, including 8-azaadenine, 8-azaguanine, and their corresponding nucleosides, have been reported to be fluorescent. And they show various applications as fluorescent probes and in biochemical process. ${ }^{70-72}$ Consequently, in 2010, Seela ${ }^{73}$ et al. synthesized 8-aza-2'-deoxyisoguanosine $\left(\mathrm{z}^{8}{ }^{8}{ }^{\prime} \mathrm{SO}_{\mathrm{d}}\right.$, 46) from the protected 8 -aza- $2^{\prime}$-deoxyguanosine $\left(\mathrm{z}^{8} \mathrm{G}_{\mathrm{d}}\right)$ in a yield of $27 \% . z^{8}$ isoG $_{d}$ shows great fluorescence that becomes stronger in alkaline conditions than at neutral $\mathrm{pH} .{ }^{73}$ Moreover, 8-azaisoguanine 47 and its $N$-methyl derivatives N3-, or N8-methyl-8azaisoguanine and N3,N8-dimethyl-8-azaisoguanine $\mathbf{4 8 - 5 0}$ were synthesized in the method of Fox ${ }^{74}$ et al. In 2012, Wierzchowski ${ }^{75}$ et al. reported these compounds 48-50 also showed 


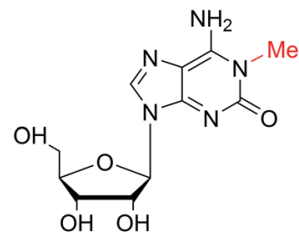

37

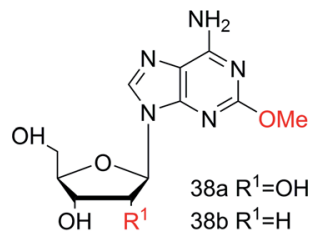

38<smiles>[R]n1c(N)c2ncn(C3OC(CO)C(O)C(O)C3O)c2nc1=O</smiles>

39

39a $\mathrm{R}^{2}=-\mathrm{CH}_{2} \mathrm{CH}=\mathrm{CH}_{2}$

$39 \mathrm{~b} \mathrm{R}^{2}=-\mathrm{CH}_{2} \quad 39 \mathrm{~g} \mathrm{R}^{2}=\mathrm{C}_{2} \mathrm{H}_{5}$

$39 c R^{2}=-\square \quad 39 R^{2}=n-C_{4} H_{9}$

$39 \mathrm{~d} \mathrm{R}^{2}=39 \mathrm{i} \mathrm{R}^{2}=\mathrm{n}-\mathrm{C}_{8} \mathrm{H}_{17}$

39e $\mathrm{R}^{2}=\prec$

39j $\mathrm{R}^{2}=\mathrm{C}_{6} \mathrm{H}_{5}$

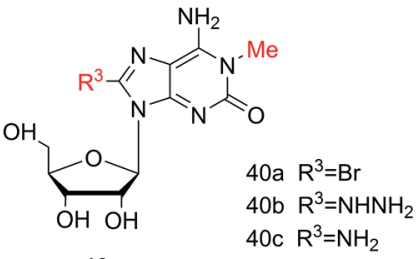

40

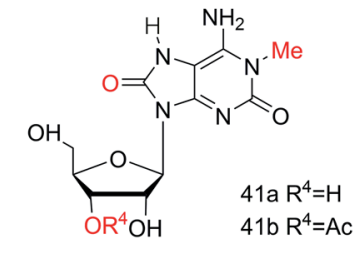

41<smiles></smiles>

$42 \mathrm{a} R^{5}=\mathrm{SH}$
$42 b \mathrm{R}^{5}=\mathrm{SMe}$
$42 \mathrm{C}^{5}=\mathrm{SCH}_{2} \mathrm{CH}_{3}$
$42 \mathrm{~d} \mathrm{R}^{5}=\mathrm{SCH}_{2} \mathrm{CH}_{2} \mathrm{OH}$
$42 \mathrm{e} \mathrm{R}^{5}=\mathrm{SPhCH}_{3}$
$42 f \mathrm{R}^{5}=\mathrm{SCH}_{2} \mathrm{Ph}$

$42 \mathrm{~g} \mathrm{R}^{5}=\mathrm{OMe}$ $42 \mathrm{~h} \mathrm{R}=\mathrm{OCH}_{2} \mathrm{CH}_{3}$ 42i $\mathrm{R}^{5}=\mathrm{CN}$ 42j $\mathrm{R}^{5}=\mathrm{NHMe}$ $42 \mathrm{k} \mathrm{R}=\mathrm{NH}\left(\mathrm{CH}_{3}\right)_{2}$ 42। $\mathrm{R}^{5}=\mathrm{NHCH}\left(\mathrm{CH}_{3}\right)_{2}$

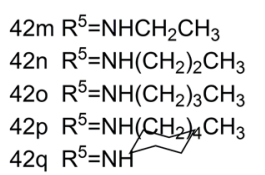$$
42 r \mathrm{R}^{5}=\mathrm{NHCH}_{2} \mathrm{CH}_{2} \mathrm{NH}_{2}
$$$$
42 \mathrm{~s} \mathrm{R}^{5}=\mathrm{NHCH}_{2} \mathrm{CH}_{2} \mathrm{OH}
$$$$
\text { 42t } R^{5}=\mathrm{NHPh}
$$$$
42 \mathrm{u} \mathrm{R}^{5}=\mathrm{NHCH}_{2} \mathrm{Ph}
$$$$
42 \mathrm{v} \mathrm{R}=\mathrm{NHCH}_{2}-\mathrm{i} \text {, }
$$

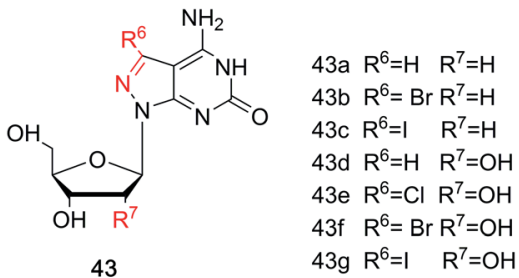

43

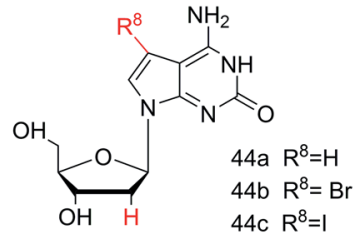

44

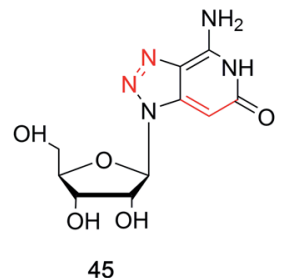

45

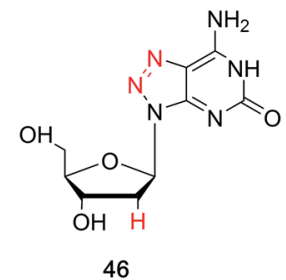

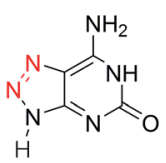

47

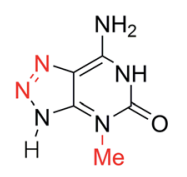

48<smiles></smiles>

49<smiles></smiles>

50

Fig. 10 Base-modified derivatives of isoG/isoguanine.

fluorescence, which is highly sensitive to the microenvironment.

4.2 Sugar-modified isoG. The structural modifications of isoG results in significant changes to its structure and functions. In addition to the previously discussed modification to the heterocycle, the glycosylation of isoG has also been studied. For example, as shown in Fig. 11, isoG ${ }_{\mathrm{d}}$ 51a was first synthesized by Kazimierczuk ${ }^{76}$ et al. in 1973. Then in 1991, Seela ${ }^{77}$ et al. improved the synthesis of iso $\mathrm{G}_{\mathrm{d}}$ from 2-halogenated-iso $\mathrm{G}_{\mathrm{d}}$, in a yield of $52-53 \%$ by photochemical methods. isoG $_{\mathrm{d}}$ has been reported to be an oxidative damage product of DNA. Oxidation shows great impacts on cells, and ROS may affect multiple cellular locations, such as the connection between DNA and proteins, as well as bases mutations. In 1995, Kamiya ${ }^{29}$ confirmed 2-hydroxy-2'-deoxyadenosine triphosphate (2-OHdATP) to be an oxidative product of dATP. But it is a minor product compared to $8-\mathrm{OH}-\mathrm{G}$, which is generally believed as a significant marker of DNA oxidation, after $\gamma$-ray irradiation and exposure to the Fenton reaction.

Fluorine-substituted nucleosides have been reported to be efficient antiviral compounds. The fluorine-carbon bond is particularly stable, and its introduction to the sugar moiety can increase the lipophilicity of a drug. ${ }^{77}$ Fluorine is generally incorporated into the 2 -position of the sugar, and it has the near radius as hydrogen and can exist in duplexes. Apart from these, fluorine also has a significant effect on the sugar 


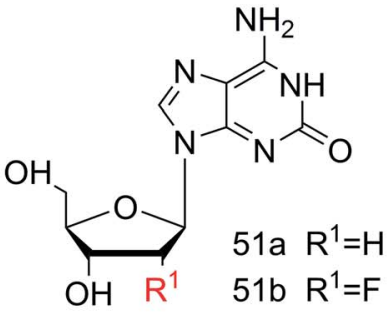

51<smiles>[R]CC(O)[C@H](O)[C@@H](O)n1cnc2c(N)n(C)c(=O)nc21</smiles><smiles>Nc1[nH]c(=O)nc2c1ncn2C1OCC2COCC1C2</smiles>

52<smiles>CC1(C)OC2OC1C(n1cnc3c(N)[nH]c(=O)nc31)OC2CO[Si](C)(C)C(C)(C)C</smiles>

53<smiles></smiles>

55<smiles>Cn1c(N)c2ncn(C3OC4OP(=O)([O-])OCC3OC4O)c2nc1=O</smiles>

56

Fig. 11 Sugar-modified derivatives of isoG.

conformation because of its strong electronegativity. Based on the characteristic of fluorine mentioned above, through deamination of 2,6-diamino-2'-deoxy-2'-fluoropurine nucleoside, Seela ${ }^{78}$ et al. first synthesized $2^{\prime}$-fluorine-2'-deoxyisoguanosine $\left({ }^{F_{i s o G}}{ }_{d}, \mathbf{5 1 b}\right.$, Fig. 11 ) in a yield of $79 \%$. Studies concerning the stability of its duplexes will be discussed in Section 5.3.4.

Some $2^{\prime} 3^{\prime}$-dideoxynucleoside derivatives have been reported to show effects such as inhibiting reverse transcription..$^{79,80}$

Table 2 Derivatives of isoG referred above found in nature or by synthesis

\begin{tabular}{|c|c|c|c|c|c|}
\hline \multirow[t]{9}{*}{ Base-modified } & 1-Methyl-isoG 37 & Natural & $1979 / 1980$ & Fuhrman et al./Quinn et al. & 49 and 50 \\
\hline & Spongosine 38a & Natural & 1951 & Bergmann et al. & 52 \\
\hline & $N 1$-Substituted isoG 39 & $\operatorname{Syn}^{a}$ & $1991 / 1981$ & Chern et al./Bartlett et al. & 48 and 56 \\
\hline & 8-Substituted-1-methyl-isoG 40 & $\operatorname{Syn}^{a}$ & $1981 / 2017$ & Bartlett et al./Firsova et al. & 56 and 57 \\
\hline & 8-Oxo-1-methyl-isoG 41a & Natural & 2017 & Thomas et al. & 57 \\
\hline & $\begin{array}{l}\text { 7-Halogenated-8-aza-7-deaza- } \\
\text { isoguanosine derivatives } \mathbf{4 3}\end{array}$ & $\operatorname{Syn}^{a}$ & $2003 / 2007$ & Seela et al. & 67 and 68 \\
\hline & $\begin{array}{l}\text { 7-Halogenated-7-deaza-isoguanosine } \\
\text { derivatives } \mathbf{4 4}\end{array}$ & $\operatorname{Syn}^{a}$ & 2007 & Seela et al. & 68 \\
\hline & 8-Aza-3-deaza-isoG 45 & $\operatorname{Syn}^{a}$ & 2004 & Jeselnik et al. & 69 \\
\hline & $\mathrm{z}^{8}$ isoG $_{\mathrm{d}} 46$ & $\operatorname{Syn}^{a}$ & 2010 & Seela et al. & 73 \\
\hline \multirow[t]{7}{*}{ Sugar-modified } & isoG $_{\mathrm{d}} 51 \mathrm{a}$ & $\operatorname{Syn}^{a}$ & 1973 & Kazimierczuk et al. & 76 \\
\hline & $\mathrm{F}_{\text {isoG }_{\mathrm{d}}} \mathbf{5 1 b}$ & $\operatorname{Syn}^{a}$ & 2015 & Seela et al. & 78 \\
\hline & $2^{\prime} 3^{\prime}$-Dideoxy-isoG 52 & $\operatorname{Syn}^{a}$ & 1999 & Kim et al. & 81 \\
\hline & $\begin{array}{l}5^{\prime} \text {-(tert-Butyldimethylsilyl)-2', } 3^{\prime}-O- \\
\text { isopropylidene-substituted isoG } 53\end{array}$ & $\operatorname{Syn}^{a}$ & 1995 & Davis et al. & 82 \\
\hline & $5^{\prime}$-Substituted-1-methyl-isoG $\mathbf{5 4}$ & $\operatorname{Syn}^{a}$ & 1981 & Bartlett et al. & 56 \\
\hline & 3,5-Anhydro-l-methyl-isoG hydriodide 55 & $\operatorname{Syn}^{a}$ & 1981 & Bartlett et al. & 56 \\
\hline & 1-Methyl-isoG cyclic $3^{\prime}, 5^{\prime}$-phosphate $\mathbf{5 6}$ & $\operatorname{Syn}^{a}$ & 1981 & Bartlett et al. & 56 \\
\hline
\end{tabular}

${ }^{a}$ Synthesized. 
Inspired by these findings, in 1999, $\mathrm{Kim}^{81}$ et al. synthesized $2^{\prime}, 3^{\prime}$ dideoxy-isoG (52, Fig. 11) from $\mathrm{G}$ in a yield of $10 \%$. And studies on its biological activities are ongoing. Besides, in 1995, the protected isoG derivatives $5^{\prime}$-(tert-butyldimethylsilyl)-2', $3^{\prime}$-Oisopropylidene-substituted isoG (53, Fig. 11) has been prepared by Davis ${ }^{82}$ et al. to study the self-assembly of isoG. So hydrogen bonds of isoG can be researched at different temperature and in different solvents. 1-Methyl-isoG (37, Fig. 10) has been identified as a natural product. And in 1981, using 1-methyl-isoG as a starting material, Bartlett ${ }^{56}$ et al. prepared several N9substituted doridosine compounds (54-56, Fig. 11). The effects of these compounds are shown later in Section 6.3. All the derivatives mentioned above can be found in Table 2 for their original sources.

\section{Structure properties of isoG}

The discovery of isoG and isoguanine in nature and their structural determination have been discussed above. In addition, we have discussed the low content and low extraction efficiency of these compounds in natural products, which led to the development of a series of synthetic methods. Next, some of the special structural properties of isoG, including its tautomerism at the single molecule level and the resulting unnatural pairing in nucleic acids, its self-assembled structures such as tetramers, the more highly ordered "sandwich-like" decamer structure, the isoG $_{4}$ quadruplexes formed in helix, the parallelstranded (ps) and antiparallel-stranded (aps) chains containing isoG will be discussed as follows.

\subsection{Tautomerism enol-keto of isoG}

The tautomeric phenomenon of nitrogen heterocycle has been widely investigated, for example, the $\mathrm{N} 1 \mathrm{H}, \mathrm{N} 3 \mathrm{H}$ and $\mathrm{O} 6 \mathrm{H}$ forms of guanine.$^{83,84}$ In a study of poly (isoG) by Golas ${ }^{85}$ et al. in 1976, the study of the tautomeric forms of isoG seems particularly important to identify correct base pairings containing isoG. In 1976, Sepiol $^{86}$ et al. reported that the tautomerism of isoG is affected by concentration, temperature, and solvent polarity. As the polarity of the solution changes, the enol ratio can vary from $5 \%$ in aqueous medium to $80 \%$ in polar solvents. They proposed that isoG is often present in solution as a mixture of enol and keto forms. isoG shows a UV absorption $310 \mathrm{~nm}$ for the $\mathrm{N} 1 \mathrm{H}$ keto form and $270 \mathrm{~nm}$ for the $\mathrm{O} 2 \mathrm{H}$ enol form. In general, the enol form $(\mathrm{O} 2 \mathrm{H})$ is favored in lower polarity solvents such as dioxane or at higher temperature in chloroform solution. ${ }^{67,86}$ In contrast, the N1H-2-oxo-6-amino form (I, Fig. 12) is mainly present in polar solvents. However, the $\mathrm{N} 3 \mathrm{H}$ form of isoG was not found until Eschenmoser and co-workers confirmed its existence in $1993 .^{87-89}$ In 1997, Switzer $^{84}$ et al. reported that isoG may possess nine tautomerism forms (I-IX, Fig. 12). The tautomeric forms I-V are the five most stable forms by gasphase calculation. They also concluded that cis-enol configuration of isoguanine is more stable than trans-enol configuration. Notably, if isoG is methylated, the enol-keto shift is faster, and the ketone 6-amino-N3H form of 9-methylisoguanine has been confirmed in solid state by Banerjee ${ }^{90}$ et al. in 1978. However, researchers have not successfully isolated the enol form of 9-methylisoguanine..$^{90}$ In 2012, Schaefer $^{44}$ et al. reported that the cis/trans enol isoguanine can be converted to the corresponding $\mathrm{N} 1 \mathrm{H}$ and $\mathrm{N} 3 \mathrm{H}$ ketone forms, respectively (Fig. 5).

In a study of pyrazolo[3,4- $d]$ pyrimidine by Seela ${ }^{68,91}$ et al. in 2007 , it is concluded that for isoG and it derivatives, a higher ratio of the ketone form results in a stronger mismatch recognition ability in duplexes. Compared to isoG $\mathrm{G}_{\mathrm{d}}$ (51a, Fig. 11) and 7-deaza-isoG ${ }_{d}$ 44a, 7-halogenated-7-deaza-isoG ${ }_{d}$ (44b, 44c, Fig. 10) prefers the ketone form, thus, the compounds $\mathbf{4 4 b}$ and 44c show a stronger mismatch ability. The proportion of the ketone form of 8-aza-7-deaza-isoG and its 7-halogenated derivatives (43, Fig. 10) are higher than the original isoG, so the mismatch recognition ability is higher. However, the effect of 7halogenation on the tautomerism of 8-aza-7-deaza-isoG $43 \mathbf{d}$ is less than that on 7-deaza-isoG ${ }_{d}$ 44a. Thus, 7-halogen substitution should not change the base recognition of 8-aza-7-deazaisoG derivatives 43a/43d. Pyrazolo[3,4- $d]$-pyrimidines 43d-43g is more enolized than pyrrolo[2,3- $d]$ pyrimidines $\mathbf{4 4}$, while isoG itself shows the highest enol content. For compound 43d-43g the equilibrium constants $\left[K_{\text {TAUT }}\right.$ (keto/enol)] range from 400 to 1200, whereas for compound 43a-43c they range from 1000 to 10 000. Therefore, these compounds are expected to exhibit better mismatch recognition than isoG.

\subsection{Mispairing}

Many researchers have studied the tolerance of base mutation that do not affect the original complementary pairing of oligonucleotides, for the purpose of expanding the genetic alphabet, designing tools for monitoring biological mechanism, and creating new gene systems. A common method is to study the pairing by inserting irregular bases. As mentioned above, isoG is an unnatural nucleoside, so the study of its base pairing is of great significance for subsequent applications. In 1962, Rich ${ }^{92}$ et al. hypothesized that isocytosine (isoC) and isoG, the isomers of $\mathrm{C}$ and $\mathrm{G}$, respectively, may make up a third Watson-Crick base pair. The complementary isoG-isoC pair would form a similar geometry to that of G-C. But there were questions as to why the isoG-isoC is not a constituent of nucleic acids. Subsequently, in 1990, Benner ${ }^{93}$ et al. confirmed the existence of the isoG-isoC base pair, as well as a second pair, isoG-T, in vitro polymerase experiments. Afterwards, evidence for isoG-isoC pair without enzymes was obtained by Horn ${ }^{94}$ et al. and Switzer ${ }^{95}$ et al. in 1995. The base pairing of isoG in the enol form is stronger than that in the ketone form, which is the first experimental evidence that tautomerism can lead to base pairing differences. The keto-enol tautomerism of isoG and the possible cis and trans conformers result in various types of mispairing and different hydrogen-bonding modes. It has been reported that in different tautomeric forms, isoG $\mathrm{d}_{\mathrm{d}}$ can pair with several natural bases, deoxycytidine, deoxythymidine, deoxyuridine, deoxyguanosine, and deoxyadenosine $\left(\mathrm{C}_{\mathrm{d}}, \mathrm{T}_{\mathrm{d}}, \mathrm{U}_{\mathrm{d}}, \mathrm{G}_{\mathrm{d}}, \mathrm{A}_{\mathrm{d}}\right.$, respectively), as well as with some special unnatural bases such as isoC $_{\mathrm{d}}$ and 5-aza-7-deaza- $\mathrm{G}_{\mathrm{d}}$ in different templates (Fig. 13). ${ }^{\mathbf{8 4 9 4 , 9 6 - 9 8}}$ On the basis of the tautomerism of the bases described above, the possible hydrogen-bonding of isoguanineisocytosine, isoguanine-uracil, isoguanine-cytosine were put 
<smiles>[R]n1cnc2c(N)[nH]c(=O)nc21</smiles>

$\mathrm{N} 1 \mathrm{H}, 2-\mathrm{oxo}, 6-\mathrm{amino}$

I<smiles>[R]n1cnc2c(N)nc(O)nc21</smiles>

$\mathrm{O} 2 \mathrm{H}, 6$-amino (trans)

VI<smiles>[R]N1C=NC2C(NN)=NC(=O)NC21</smiles>

2-oxo,N3H,6-amino

II<smiles>[R]n1cnc2c(=N)[nH]c(O)nc21</smiles>

$\mathrm{N} 1 \mathrm{H}, \mathrm{O} 2 \mathrm{H}, 6-$-imino (trans)

VII<smiles>[R]N1C=NC2C(=N[2H])NC(=O)NC21</smiles>

$\mathrm{N} 1 \mathrm{H}, \mathrm{N} 3 \mathrm{H}, 2-\mathrm{oxo}, 6-\mathrm{imino}$ (trans)

III<smiles>[R]n1cnc2c(=N)nc(O)[nH]c21</smiles>

$\mathrm{N} 3 \mathrm{H}, \mathrm{O} 2 \mathrm{H}, 6-\mathrm{imin}$ o (cis)

VIII<smiles>[R]N1C=NC2C(=N[2H])NC(=O)NC21</smiles>

$\mathrm{N} 1 \mathrm{H}, \mathrm{N} 3 \mathrm{H}, 2-\mathrm{oxo}, 6-\mathrm{imino}(\mathrm{cis})$

IV<smiles>[R]n1cnc2c(=N)nc(O)[nH]c21</smiles>

$\mathrm{N} 3 \mathrm{H}, \mathrm{O} 2 \mathrm{H}, 6-$ imino (trans)

IX<smiles>[R]n1cnc2c(N)nc(O)nc21</smiles>

$\mathrm{O} 2 \mathrm{H}, 6$-amino (cis)

V

Fig. 12 Tautomerism of isoG.

forward (Fig. 13). ${ }^{84}$ And in 2003, the impact of the temperature and the adjacent base pairs on base pairings of isoguanine was investigated by Maciejewska ${ }^{99}$ et al. They concluded both affect base-pairing by changing the polarity of the solution around the isoguanine to cause tautomerism. The temperature was found to have only a slight influence on the base pairing. The $3^{\prime}$ adjacent base affects the tautomerism, while the $5^{\prime}$-neighbor<smiles>[2H]c1c2c3ncn(C)c3nc-2ncn1[TlH]</smiles>

isoG ${ }_{d}[\mathrm{O} 2 \mathrm{H},(c i s)]-\mathrm{A}_{d}$

a<smiles></smiles>

iso $\mathrm{G}_{\mathrm{d}}(\mathrm{N} 1 \mathrm{H}, 2-\mathrm{oxo}, 6$-amino $)-\mathrm{U}_{\mathrm{d}}$

d

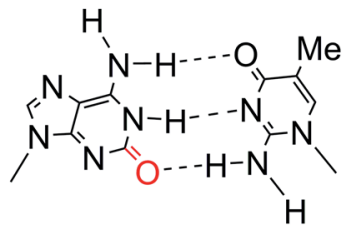

iso $G_{d}(N 1 H, 2-o x o, 6-a m i n o)-5-$ methyl-iso $_{d}$ isoG ${ }_{d}\left(N 1 H, 2-o x o, 6\right.$,amino)-5-aza-7-deaza- $G_{d}$

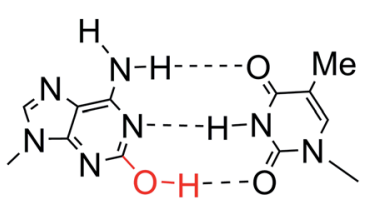

isoG $\mathrm{G}_{\mathrm{d}}[\mathrm{O} 2 \mathrm{H},(c i s)]-\mathrm{T}_{\mathrm{d}}$

b

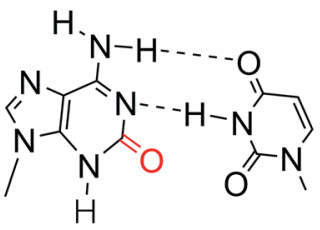

iso $G_{d}(N 3 H, 2-o x o, 6-a m i n o)-U_{d}$

e

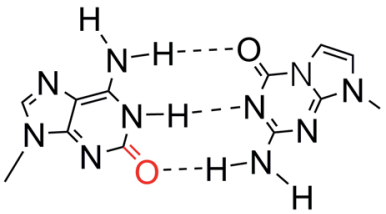

$\mathrm{h}$<smiles></smiles>

isoG $\mathrm{d}_{\mathrm{d}}(\mathrm{N} 1 \mathrm{H}, \mathrm{N} 3 \mathrm{H}, 2-\mathrm{oxo}, 6$-imino $)-\mathrm{C}_{\mathrm{d}}$

C<smiles></smiles>

iso $\mathrm{G}_{\mathrm{d}}[\mathrm{O} 2 \mathrm{H}$, (trans) $]-\mathrm{U}_{\mathrm{d}}$

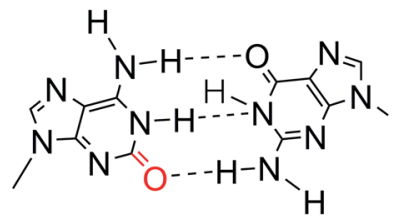

iso $G_{d}(N 1 H, 2-o x o, 6-a m i n o)-G_{d}$

Fig. 13 Base pairs of isoG. 
can not, because the $5^{\prime}$-terminal is not at the polymerase active site for the stacking with template.

In 1986, Jaworski ${ }^{96}$ et al. carried out experiments to explore the interaction energies of isoguanine-isocytosine and isoguanineuracil, and compared them with energies of natural base pairs guanine-cytosine, adenine-thymine/adenine-uracil. It was found that isoguanine-uracil interaction energy is smaller than that of guanine-cytosine and isoguanine-isocytosine but stronger than that of adenine-thymine/adenine-uracil pairs. Additionally, isoguanine-isocytosine pairing is slightly stronger than guanine-cytosine pairing. And iso $\mathrm{G}_{\mathrm{d}}-5$-methyl-isoC $\mathrm{C}_{\mathrm{d}}$ pair was reported to be isoenergetic with the $\mathrm{G}-\mathrm{C}$ pair, and each base can effectively identify mismatches in synthetic oligonucleotides, by Horn ${ }^{94}$ et al. in 1995 and Switzer ${ }^{84}$ et al. in 1997. The isoguanine-cytosine and uracil-adenine base pairs have the same energy. In 1997, using ab initio data from calculations combined with thermodynamic data, Switzer ${ }^{84}$ et al. concluded the reason why isoguanine-isocytosine shows unnatural stability may be that isoguanine adopts a carbonyl-imino form.

Isoguanine is a modified base, so its enzymatic recognition and removal have aroused wide interest among scholars. Various DNA and RNA enzymes can catalyze the recognition of different bases by hydrogen bonding interactions. Thus, the enzymological properties of these varied base pairs have been investigated to explore whether they are incorporated into duplexes by DNA and RNA polymerases, and, if so, under what conditions. It has been demonstrated that various enzymes catalyze the entry of isoG into the nucleotide chains in vitro (Table 3). For the first time, Switzer ${ }^{\mathbf{1 0 0}}$ et al. reported that disoGTP can be incorporated opposite T/isoC by the Klenow fragment (KF) of E. coli DNA polymerase (pol) I and T7 RNA polymerase in 1989. Then in 1993, they reported that in different templates, avian myeloblastosis virus (AMV) reverse transcriptase can enhanced the formation of isoG-isoC, and isoG-U base pairs via T7 RNA pol. ${ }^{101}$ And T7 RNA pol has a preference in catalyzing the incorporation of $U$ over isoC. However, T4 DNA pol rejected isoguanine's incorporation under reported experimental conditions. Moreover, in 1993, Dervan ${ }^{\mathbf{1 0 2}}$ et al. reported that 5-methyl-isoC $\mathrm{C}_{\mathrm{d}}$ can direct the incorporation of N6-(6-aminohexyl)-isoG into the transcribed RNA by T7 RNA pol. And this amino group affords site-specifically modified RNA sequences beneficial for future studies after transcription. Until then, the possibility of isoG opposite $\mathrm{A} / \mathrm{G}$ and the incorporation by mammalian polymerase were not investigated. Subsequently, in 1995, in vitro DNA synthesis, Kamiya ${ }^{31}$ et al. reported that deoxythymidine monophosphate (dTMP) and deoxyadenosine monophosphate (dAMP) can be incorporated to pair with isoG by KF of E.coli DNA pol I, recombinant rat DNA pol $\beta$ and calf thymus DNA pol $\alpha$. And deoxyguanosine monophosphate (dGMP) can pair with isoG by KF of E.coli DNA pol I. They also concluded that d-isoGTP can mismatch with T/C (showing a preference for T) using mammalian (calf) DNA pol $\alpha .{ }^{29}$ Whereas d-isoGTP can only pair with $\mathrm{T}$ by KF of E.coli DNA pol I. In 1996, using calf thymus DNA pol $\alpha$ and recombinant rat DNA pol $\beta$, they confirmed the dTMP and deoxycytidine monophosphate (dCMP) pairs with isoG. ${ }^{103}$ Whereas dTMP and dGMP were incorporated to form base pairs with isoG by KF of DNA pol I. In addition, human immunodeficiency virus 1 reverse transcriptase (HIV-1RT) has a high tolerance for nonstandard bases, indicating that it promotes nonstandard base pairing containing iso $\mathrm{G}_{\mathrm{d}}$, and thus preventing HIVinfected cells from being recognized and dying in the cell's $\mathrm{S}$ phase. ${ }^{\mathbf{1 0 4 , 1 0 5}}$ Then in 1998, Lutz $^{\mathbf{1 0 6}}$ et al. reported that compared to eukaryotic DNA polymerases, the incorporation of $\mathrm{T}$ or $\mathrm{U}$ by HIV-1RT to mismatch with d-isoGTP is more efficient, whether dATP exists or not. In 2000, Kamiya ${ }^{107,108}$ et al. reported the 2$\mathrm{OH}$-dATP can pair with $\mathrm{T}$ and $\mathrm{G}$ using the $\alpha$ (catalytic) subunit of E. coli DNA pol III and KF of DNA pol I. Above all, the incorporation of isoG depends on the types of polymerases, as well as the sequence contexts in various templates.

In 1975, Mantsch $^{\mathbf{4 1}}$ et al. reported that isoguanine nucleotides are not recognized by the mitochondrial endometrial translocation enzyme system, but they can be well recognized by mitochondrial phosphatases in the inter-membrane space. They are also involved in phosphoryl group transfer reactions. These reactions are catalyzed by pyruvate kinase, phosphofructokinase and hexokinase. Additionally, in 1998, Kamiya ${ }^{\mathbf{1 0 9}}$ et al. reported that isoguanine opposite thymine/cytosine cannot be moved by a glycosylase-type mechanism in rat organs. In bacteria such as in $E$. coli, there are some specific enzymes for the removal of unnatural base from damaged nucleic acid. In 2011, Raushel ${ }^{110}$ et al. reported that cytosine deaminase (CDA) from E. coli can catalyze the deamination of isoguanine to xanthine. However, in 2000, Kamiya ${ }^{111,112}$ et al. demonstrated that the removal of isoguanine by the MutY and MutM proteins of $E$. coli is slow because of poor affinity. Surprisingly, they reported that among the known akin nucleotide substrates, the nucleotide forms of isoG $(2-\mathrm{OH}$ ATP and 2-OH-dATP, where ATP is adenosine triphosphate and dATP is deoxyadenosine triphosphate) are substrates with the highest affinity for the human MTH1 (hMTH1) protein, which is a hydrolytic enzyme. ${ }^{113,114}$ Moreover, 2-OH-dADP and 8-OH-dGDP (dADP and dGDP are deoxyadenosine diphosphate and deoxyguanosine diphosphate, respectively) can competitively inhibit the effect of hMTH1 on 2-OH-dATP and 8-OH-dGTP (dGTP is

Table 3 Enzymes incorporating isoG opposite different natural/unnatural nucleosides

\begin{tabular}{|c|c|c|c|c|c|c|c|c|}
\hline Enzymes & $\begin{array}{l}\text { E. coli DNA } \\
\text { pol I }\end{array}$ & $\begin{array}{l}\text { E. coli DNA } \\
\text { pol III }\end{array}$ & DNA pol $\beta$ & DNA pol $\alpha$ & T7 RNA pol & $\begin{array}{l}\text { AMV reverse } \\
\text { transcriptase }\end{array}$ & $\mathrm{T} 4 \mathrm{pol}$ & HIV-1RT \\
\hline lispairing with isoG & $\mathrm{T} / \mathrm{isoC} / \mathrm{A} / \mathrm{G}$ & $\mathrm{T} / \mathrm{G}$ & $\mathrm{T} / \mathrm{A} / \mathrm{C}$ & $\mathrm{T} / \mathrm{A} / \mathrm{C}$ & $\mathrm{U} / \mathrm{T} / \mathrm{isoC}$ & isoC & $-^{a}$ & $\mathrm{~T} / \mathrm{U}$ \\
\hline References & $29,31,100,103$ & 107 and 108 & 31 and 103 & 29, 31 and 103 & 100 and 101 & 101 & 101 & 106 \\
\hline
\end{tabular}
107 and 108

${ }^{a}$ T4 pol do not catalyze any nucleosides opposite isoG under experimental conditions. 
deoxyguanosine triphosphate), which indicates that hMTH1 takes effect on the damaged substances via the same receptor. ${ }^{114}$

\subsection{Self-assembling of isoG}

We have discussed the tautomeric forms of isoG in different solvents and the various base pairs catalyzed by different DNA and RNA enzymes above. Now, we will describe several types of advanced structures such as tetramers, decamers, oligonucleotides, and ps/aps strands that form based on the self-assembly properties of isoG. Self-assembly is a process where substances combine into a supramolecular system through intermolecular forces, such as electrostatic and hydrophobic interactions. The discoveries of poly(isoguanylic acid), the oligonucleotide $d\left(\mathrm{~T}_{4^{-}}\right.$ isoG $\mathrm{T}_{4}$ ), and $\mathrm{G}$-quartets indicate that isoG may also selfassemble into supramolecular structures. In fact, both $\mathrm{G}$ and isoG can self-assemble into supramolecular systems, such as supramolecular gel by hydrogen-bonding, $\pi-\pi$ stacking, and hydrophobic interactions. And these structures show a wide range of applications in material science, medical chemistry, and nanotechnology etc. As mentioned before, isoG differs from $\mathrm{G}$ in that the $\mathrm{C} 2$ carbonyl and $\mathrm{C} 6$ amino groups are transposed. This minor change causes significant differences between isoG and G. In particular, the variation in hydrogen bond donors and acceptors affects the hydrogen-bonded systems, resulting in great changes in self-assembled supramolecular structures. For $\mathrm{G}$, the angle between the hydrogen bond donor (N1 amide and $\mathrm{N} 2$ amino) on its Watson-Crick face and the receptor (N7 and O6) in the Hoogsteen face is $90^{\circ}$, and this is favorable for the formation of planar tetrads (Fig. 14). ${ }^{\mathbf{1 1 5 , 1 1 6}}$ On the contrary, the isoG donor-receptor angle of $67^{\circ}$ prefers cyclic pentad (Fig. 14). In 1994, Davis ${ }^{82}$ et al. raised that for isoG, there are two prerequisites for self-association. One is that the hydrogenbonding receptors of isoG $(\mathrm{O} 2-\mathrm{C} 2-\mathrm{N} 3)$ are close to $180^{\circ}$, whereas the N7-C5-C6-O6 bond of G is nonplanar. And the ribose of isoG, as well as the hydrogen-bond acceptors, are more likely to form hydrogen bonds in the lower position of purine. ${ }^{117,118}$ The other prerequisite is the formation of hydrogen bond between the $\mathrm{N} 6 \mathrm{H}$ proton and adjacent isoG monomer $\mathrm{O} 2^{\prime}$. In contrast, $\mathrm{G}$ is unlikely to form such a hydrogen bond because the hydrogen bond acceptor O6/N7 and the glycosyl group are in opposite positions in the heterocycle. ${ }^{82}$ This is also an important reason why isoG selfassembled oligonucleotides are more stable than the corresponding G self-assembled oligonucleotides. ${ }^{119}$ It has also been proposed that isoG has three variable $\mathrm{N}$ protons that are important for supporting the self-assembly. ${ }^{82} \quad \mathrm{C}^{2} \mathrm{NH}_{\mathrm{A}}$ and $\mathrm{C} \mathrm{NH}_{\mathrm{B}}$ (Fig. 14) rotates slowly, allowing the exocyclic amino group to form a strong hydrogen bond, and the third proton $\mathrm{N} 1 \mathrm{H}$ is confirmed based on nuclear Overhauser effect (NOE) and UV studies in $\mathrm{CDCl}_{3} .{ }^{82}$

5.3.1 The tetramer model of isoG. As shown in Fig. 14, without cations, some free $G$ lipophilic derivatives such as $G_{d}$ can only self-assemble to different ribbons by taking $\mathrm{N} 3$ as a hydrogen-bonding receptor. ${ }^{\mathbf{1 2 0}}$ And in 2002 , Gottarelli ${ }^{\mathbf{1 2 1}}$ et al. reported that some lipophilic derivatives are potential gelators. However, for isoG, self-assembly into tetramers or decamers without cations is possible. In the presence of cations, G-quartet was identified as the basis of the self-assembling of G. ${ }^{122}$ It is widely accepted that G-quartet takes shape via eight Hoogsteen hydrogen-bonds, and a central cavity containing four oxygens that bind to cation through ion-dipole interactions. The stability of G-quartets varies with different radii and charges of the cations. In 1978, Becker ${ }^{123}$ et al. reported that G-quartets are stabilized in the presence of sodium ion $\left(\mathrm{Na}^{+}\right)$and potassium ion $\left(\mathrm{K}^{+}\right)$. In 1994, using 2D nuclear Overhauser spectroscopy (NOESY) and 1D NOE experiments, the isoG tetramer, a basic unit of isoG self-assembled structures, was confirmed. When two nuclei (A and B) are close to each other in space and have strong mutual relaxation, NOE occurs. This means that when A is saturated by irradiation, its energy is transferred to B, so that the energy absorbed by $\mathrm{B}$ increases and the resonance signal also increases. The specific NOEs between the exocyclic $\mathrm{C}_{6 \mathrm{NH}}$
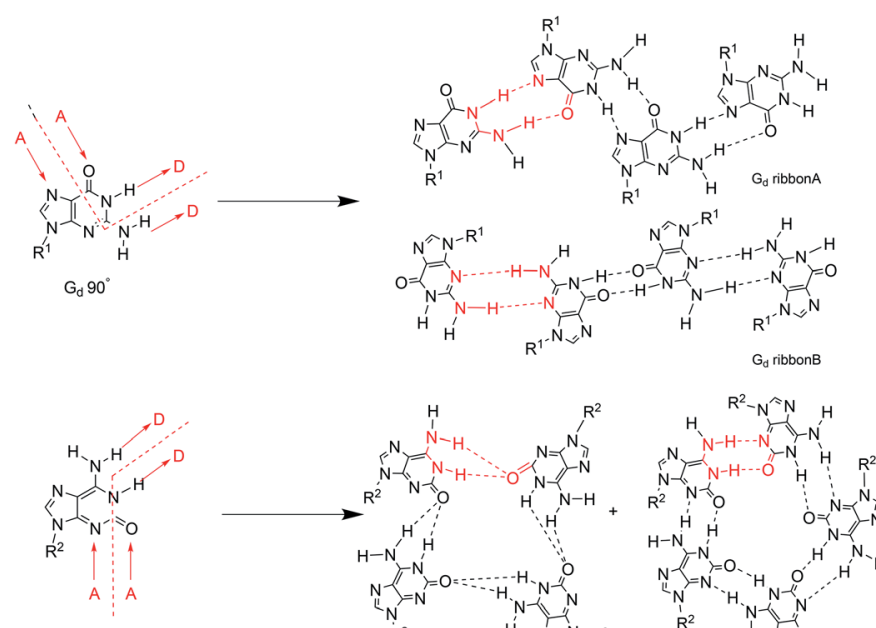

isoG $67^{\circ}$

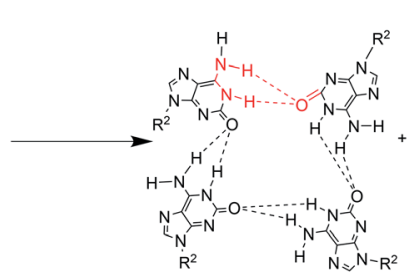

(isoG) 4

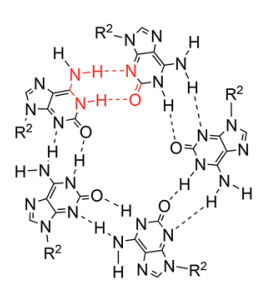

(isoG) $)_{5}$
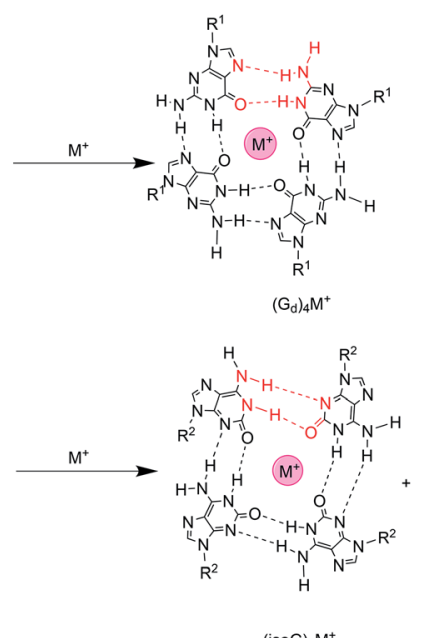

(isoG) ${ }_{4} \mathrm{M}^{+}$
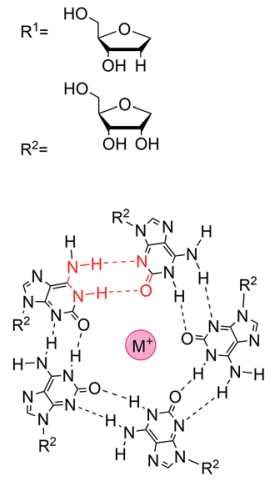

(isoG) $)_{5} \mathrm{M}^{+}$

Fig. 14 Self-assembly of isoG and G with/without cations. 
amino proton and the adjacent ribose $\mathrm{H} 1^{\prime}$ and $\mathrm{H} 2^{\prime}$ protons are confirmation of isoG self-association. ${ }^{82}$ Only the isoG tetramer model conforms with the observed NOEs.

Similar to the interaction of the cations with G, alkali ions have a great influence on the self-assembled structures of isoG. Different ions have been titrated into pure isoG mononucleoside in $d_{6}$-acetone to identify the different structures. ${ }^{82}$ Tetramerization with lithium ion $\left(\mathrm{Li}^{+}\right)$is unstable because $\mathrm{Li}^{+}$is too small for the central cavity. $\mathrm{Li}^{+}$may be combined with the $\mathrm{O} 2$ or N3 hydrogen-bond donors to hinder hydrogen-bond formation. A low concentration of $\mathrm{Na}^{+}$can stabilize the tetramer, probably via ionic coupling. But no new NMR peaks have been observed with $\mathrm{Na}^{+}$, which indicates that no higher-ordered selfassemblies, such as stacking structures, are formed in the presence of $\mathrm{Na}^{+}$. Nevertheless, high concentrations of $\mathrm{Na}^{+}$ destroy isoguanine tetramers, probably for the same reason as that for $\mathrm{Li}^{+}$. Notably, the addition of $\mathrm{K}^{+} /$barium ion $\left(\mathrm{Ba}^{2+}\right)$ form octamers, presenting a new peak with a sandwich structure. ${ }^{12,82}$ And $\mathrm{K}^{+} / \mathrm{Ba}^{2+}$ enhanced the thermal stability compared to the original tetramer. Moreover, the $\mathrm{Ba}^{2+}$ octamer is more stable than $\mathrm{K}^{+}$octamer.

The hydrogen-bonding modes are different in the isoG tetramer in the presence and absence of cations. Next, the hydrogen bonds in alkali-metal-free isoG tetrad and pentad structures will be introduced. In 2003, Meyer ${ }^{124}$ et al. proposed that the hydrogen-bond modes in tetrad and pentad are different (Fig. 14), one difference is that the $\mathrm{N} 1-\mathrm{H} 1 \cdots \mathrm{O} 2$ hydrogen bond ( $\mathrm{H}$ bond) in the tetrad is longer than that in the pentad. The other is the tetrad $\mathrm{N} 6-\mathrm{H} 6 \cdots \mathrm{O} 2 \mathrm{H}$ bond forms a crossing hydrogen bond with the $\mathrm{N} 1-\mathrm{H} 1 \cdots \mathrm{O} 2 \mathrm{H}$ bond. Whereas two hydrogen bond, $\mathrm{N} 1-\mathrm{H} 1 \cdots \mathrm{O} 2$ and N6-H6 $\cdots \mathrm{N} 3$ are formed without crossing in the pentad. Besides, the second $\mathrm{H}$ bond N6-H6 $\cdots \mathrm{N} 3$ in pentad is shorter than the second bond $\mathrm{N} 6-\mathrm{H} 6 \cdots \mathrm{O} 2$ in tetrad. When the ions are added to the isoG solution, there are no crossing hydrogen bonds occurring. In other words, alkali ions can affect the crossing hydrogen-bond mode of the protected isoG tetramer $(\mathbf{5 3})_{4}$ to form independent $\mathrm{N} 6-\mathrm{H} 6 \cdots \mathrm{N} 3$ and $\mathrm{N} 1-\mathrm{H} 1 \cdots \mathrm{O} 2$ hydrogen bonds (Fig. 14). This is not surprising because base-cation linkages are usually stronger than base-base linkages for isoG. That is, the cation interactions are the dominant contribution to the interaction energy. As a result of metal cations present in the cavity, the base-base hydrogen bond in the tetrad is shorter than in the pentad, and the distance between cation and $\mathrm{O} 2$ is also shorter. It indicates the hydrogen bond distance is shortened in the presence of alkali ions, and this effect is more pronounced for $\mathrm{Li}^{+}$and decreases with increasing ion size. From $\mathrm{Li}^{+}$to cesium ion $\left(\mathrm{Cs}^{+}\right)$, the distance between $\mathrm{O} 2$ and the cation increases. Further, larger ions result in smaller connection energies between the ion and $\mathrm{C} 2$ carbonyl group.

The protected isoG tetramer $(\mathbf{5 3})_{4} \cdot \mathbf{M}^{+}$is stabilized by the hydrogen-bond system of the outer ring and the inner ring (Fig. 14). The inner ring is composed of four hydrogen bonds formed between the imino $\mathrm{N} 1 \mathrm{H}$ proton and the $\mathrm{C} 2$ carbonyl oxygen of an adjacent isoG. The outer ring is comprised of hydrogen bonds between $\mathrm{N} 6 \mathrm{H}$ and $\mathrm{N} 3 \mathrm{H}$ of the adjacent monomer. Four nonbonded C2 oxygen atoms point to the cavity, interacting with metal alkali ions, and selectively bind to monovalent or divalent cations to form a stable complex. The presence of multiple metal ions causes different changes to hydrogen-bond model, and metal cations are often required to stabilize hydrogen-bonded macrocycles. The self-assembled structures of isoguanine with different metal ions varies. For example, the tetramer of isoG is strongly nonplanar except with $\mathrm{Li}^{+}$, whereas the pentamer is often planar. In fact, most nonplanar structures converge into planar structures, so most of the known tetrad/pentad structures are planar, which is more stable. However, there is no selectivity over monovalent and divalent ions. That is, there is no difference in affinity for different charge numbers. Moreover, the tetrad has strong selectivity and preference for small ions. However, for large ions, there is no preference between the tetrad and pentad. The energy of (isoG) $)_{4} \cdot \mathrm{Li}^{+}$tetrad is higher than that of its pentad, whereas the energy of the pentad with a larger radius is higher

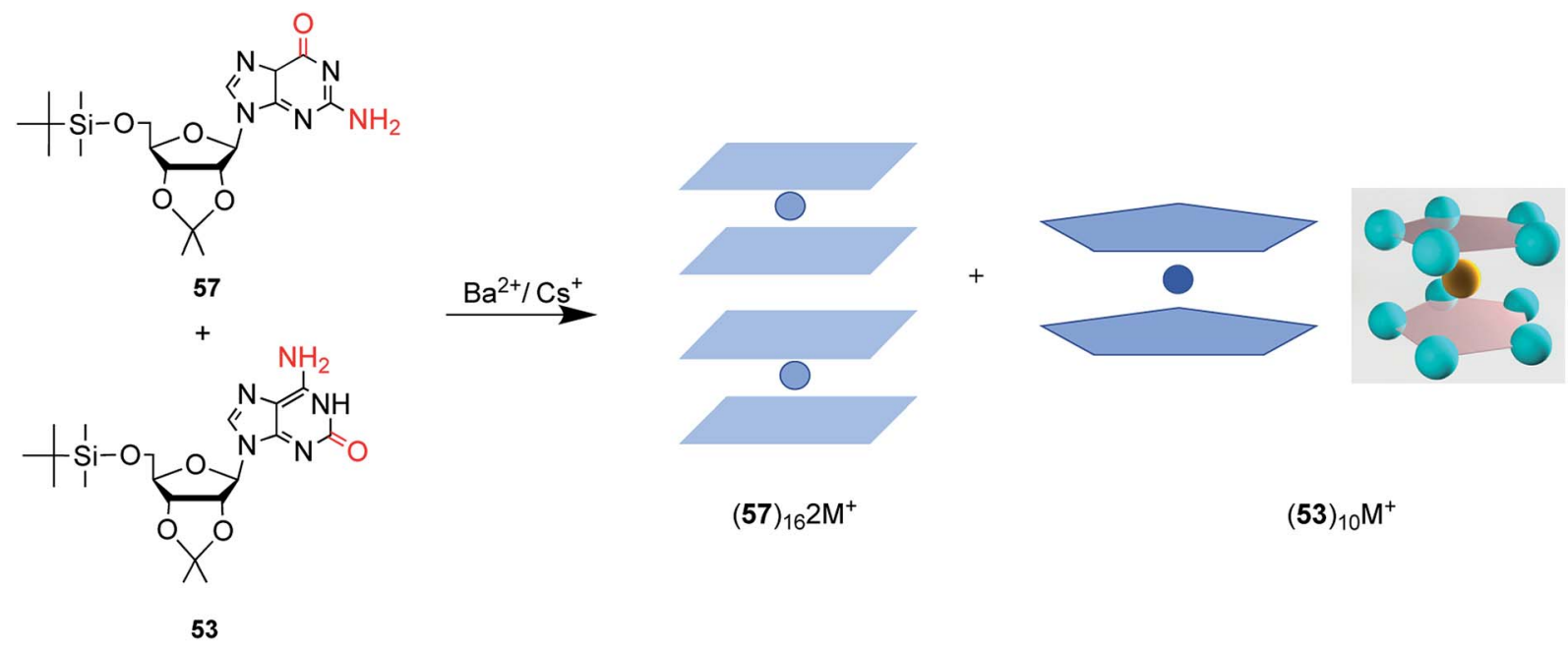

Fig. 15 The protected $\mathrm{G}$ and isoG self-assemble and stack into hexadecamer and decamer respectively in the presence of $\mathrm{Ba}^{2+}$. 
than the corresponding tetrad energy. The energies of the planar tetrad structures are relatively low; i.e., they are more stable. And the metal-free and (isoG) $)_{5} \cdot \mathrm{K}^{+} /$rubidium ion $\left(\mathrm{Rb}^{+}\right)$ pentad energies are also relatively low. $\mathrm{Li}^{+}$and $\mathrm{Na}^{+}$ions are too small for the pentameric cavity, whereas $\mathrm{Cs}^{+}$is too large to be in the cavity so it may sit over the isoG $_{5}$ pentad plane. The protected isoG (53, Fig. 11) can also self-associate in the gas phase and studies into this fact are ongoing.

5.3.2 Sandwiched structure formed by isoG. In 2000, by Xray crystallography, Davis ${ }^{\mathbf{1 2 5}}$ et al. showed that the protected $\mathrm{G}$ (57, Fig. 15) can stack into an ordered hexadecamer. And solidstate decamers have been obtained with $\mathrm{Ba}^{2+}$ and strontium $\left(\mathrm{Sr}^{2+}\right)$ in 2001 by his group. ${ }^{\mathbf{1 2 0 , 1 2 6 - 1 2 8}}$ They also showed the role of organic anions in the cation-filled quadruplexes, which predominate in solution. ${ }^{129}$ In 2000 , they reported isoG, an isomer of $\mathrm{G}$, can also stack into a sandwiched structure (53) ${ }_{10} \cdot \mathrm{Cs}^{+}$(Fig. 15), comprising two hydrogen-bonded isoG pentads. ${ }^{130}$ This structure forms in both solution and solid state. Two-side views of the crystal sandwich structure are shown (Fig. 16): a overlooking view showing the two pentameric tail-tail connections that directly overlap with ten chemically equivalent isoG units having $\mathrm{Cs}^{+}$and ten carbonyl groups in the center; the side view shows a sandwich model with $\mathrm{Cs}^{+}$as the bisector of the plane. In 1999, depending on conventional NMR, an inaccurate isoG pentamer structure was confirmed by Davis $^{\mathbf{1 3 1}}$ et al., and was generally accepted for a long time. But advances in experimental instruments have revealed that the use of conventional NMR is insufficient to probe the distinction

A

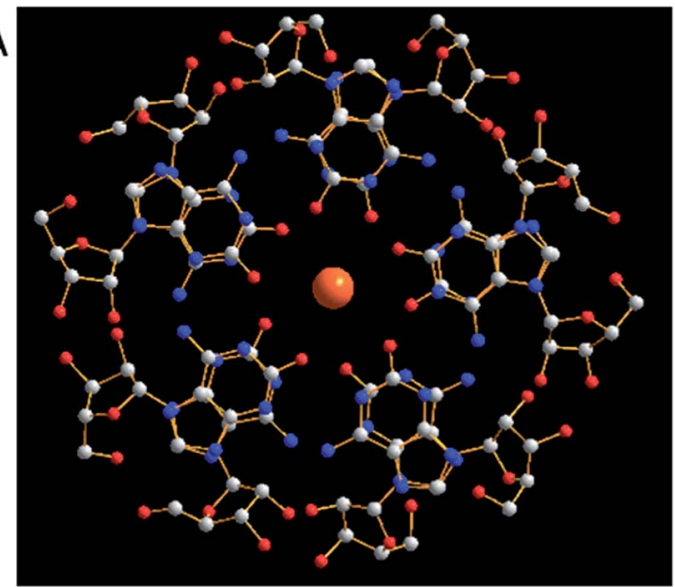

B

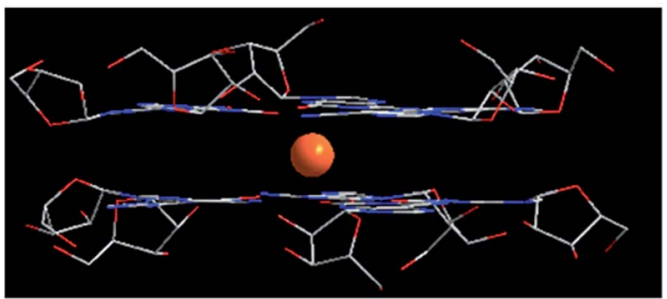

Fig. 16 (A) A top view of X-ray crystal structure of $(53)_{10} \cdot \mathrm{Cs}^{+}$. Two pentamers directly overlap with ten chemically equivalent isoG units, having $\mathrm{Cs}^{+}$(yellow) and ten carbonyl groups in the center. $C$ atoms are grey, $\mathrm{N}$ atoms are blue, $\mathrm{O}$ atoms are red. (B) A sandwich model with $\mathrm{Cs}^{+}$as the bisector of the plane. Anions are omitted for clearness. between highly symmetrical supramolecular structures. And it is also difficult to determine the structure of a self-assembly system similar to its monomeric and oligomeric structures. Consequently, in 2007, they used the present diffusion NMR, which uses pulse field gradient techniques, to determine the exact size and molecular shape in solution. ${ }^{\mathbf{1 3 2}}$ As a result, the wrong pentamer structure $(\mathbf{5 3})_{5} \cdot \mathrm{M}^{+}$was overturned, and the correct $(53)_{10} \cdot 2 \mathrm{M}^{+}$or singly charged decamer $(53)_{10} \cdot \mathrm{M}^{+}$structures were identified. Of the two structures, the latter $(53)_{10} \cdot \mathbf{M}^{+}$ form is more commonly seen. If there are more cations, then the $(53)_{10} \cdot 2 \mathrm{M}^{+}$sandwiched structure is obtained, with one metal ion in the middle and the other one in the pentad. In addition, for $(53)_{10} \cdot 2 \mathrm{M}^{+}$, another structure having two cations in the pentads was rejected because it is impossible on the basis of combined anion limited. $(53)_{10} \cdot 2 \mathrm{M}^{+}$can more easily bind anions than $(53)_{10} \cdot \mathbf{M}^{+}$, but it has been shown that anions are not involved in the self-assembly process.

isoG is selective for the largest alkali cation, $\mathrm{Cs}^{+}(r=1.67 \AA)$, whereas G-quartets have a preference for $\mathrm{K}^{+}(r=1.33 \AA){ }^{132}$ Importantly, in the presence of $\mathrm{Cs}^{+}$, isoG only formed the $(53)_{10} \cdot \mathrm{Cs}^{+}$structure. However, for other cations such as $\mathrm{Li}^{+}$, $(53)_{10} \cdot \mathrm{M}^{+}$and $(\mathbf{5 3})_{10} \cdot 2 \mathrm{M}^{+}$structures are formed, and stay nonstop transition between each other. ${ }^{132}$ Notably, $(53)_{10} \cdot 2 \mathrm{~K}^{+}$ directly comes from two pentamers rather than by the addition of more $\mathrm{K}^{+}$. Furthermore, in 2014, Rodriguez ${ }^{\mathbf{1 3 3}}$ et al. reported that small dendritic molecules containing isoG can also selfassemble into a decameric nucleodendrimers, even without cations. And they demonstrated the existence of $\mathrm{G}$ analogs can promote the formation of decameric nucleodendrimers, but are not involved in decameric structures. Experiments to explore the abilities of different ions to induce nucleodendrimers identified that the isoG-based nucleodendrimers show a preference for $\mathrm{Cs}^{+}$over $\mathrm{K}^{+}$, which reflects the fact that the cavity size is more suitable for the large radius of $\mathrm{Cs}^{+}$. In addition to the above, in 2002, from the NMR spectrum, Davis ${ }^{\mathbf{1 3 4}}$ et al. concluded that $\mathrm{G}$ and isoG self-assemble independently in the presence of $\mathrm{Cs}+/ \mathrm{Ba}^{2+}$, rather than form crosslinked structures (Fig. 15). However, in $\mathrm{CD}_{2} \mathrm{Cl}_{2}$ where there is no cation, $\mathrm{G}$ and isoG are crosslinked..$^{\mathbf{1 3 , 1 2 9 , 1 3 4}}$

Moreover, in 2000, Davis ${ }^{13}$ et al. found that (D,L)-isoG $(53,59$, Fig. 17) undergoes enantiomeric self-recognition in solution containing $\mathrm{Cs}^{+}$. Then in 2001, they found that the protected (D,L)$\mathrm{G}(\mathbf{5 7}, \mathbf{5 8}$, Fig. 17$)$ can self-associate with diastereoselectivity in $\mathrm{Ba}^{2+}$-containing solutions, yielding two homochiral Gquadruplexes $(57)_{16} \cdot 2 \mathrm{Ba}^{2+} \cdot \mathrm{pic}^{-}$and $(58)_{16} \cdot 2 \mathrm{Ba}^{2+} \cdot 4 \mathrm{pic}^{-126}$ But in the presence of $\mathrm{K}^{+}$, (D,L)-G forms a diastereomeric mixture. As mentioned above, hydrogen bonds can take shape between neighboring isoG ribose residue to help conquer the entropic demands in relation to enantiomeric self-sorting, whereas this does not occur for G. Such hydrogen bonds can transfer conformational information between pentameric isoG to ensure homochiral conformation. And the achiral $\mathrm{Cs}^{+}$promotes the enantioselectivity of isoG, thus promoting formation of the $\mathrm{Cs}^{+}$ sandwich meso decamer, $(53)_{5} \cdot \mathrm{Cs}^{+} \cdot(59)_{5} \cdot \mathrm{Ph}_{4} \mathrm{~B}^{-}$, as determined by X-ray crystal structure analysis. However, enantioselectivity is not possible with other ions. 
5.3.3 Oligonucleotide aggregates $\mathbf{d}\left(\mathbf{T}_{4} \text { isoG }_{4} \mathbf{T}_{4}\right)_{4}$. The tetramer and decamer structures of isoG have been summarized above, next, the isoG-based aggregated structures in duplexes will be talked about. In 1984, Blackburn ${ }^{\mathbf{1 3 5}}$ et al. reported that some $\left(\mathrm{G}_{\mathrm{d}}\right)_{4}$ aggregates are natural parts of telomeres. This has aroused great interest in G-quadruplexes. In 1989, Williamson ${ }^{136}$ et al. found that oligonucleotides including short runs of $G$, such as $d\left(T_{4} G_{4} T_{4}\right)$, can form four-stranded nucleic acid structure named G-quadruplexes. And the fundamental structure is the G-quartet composed of four G units interacting via Hoogsteen hydrogen bonds in planar (Fig. 14). G-quartets stacked in a helical mode via $\pi-\pi$ interactions are stabilized by cations such as $\mathrm{K}^{+}$and $\mathrm{Na}^{+}$(preference $\mathrm{K}^{+}>\mathrm{Na}^{+}$). And with cations linked with $\mathrm{O} 6$ of $\mathrm{G}$ in the interior channel, G-quartets show a parallel/antiparallel orientation of strands. The oligonucleotides containing short runs of $\mathrm{G}$ can self-assemble into higher aggregates, which can be classified depending on their molecularity [i.e., unimolecular (monomer), bimolecular (dimer), and tetraplex (tetramer)] or in terms of their strand orientation (i.e., chair or basket) (Fig. 18a-f). ${ }^{137-139}$ In 1996, based on ion-exchange HPLC and circular dichroism (CD) spectroscopy, Seela ${ }^{\mathbf{1 4 0}}$ et al. demonstrated the identification of an isoG-containing oligonucleotide quartet $\mathrm{d}\left(\mathrm{T}_{4} \mathrm{isoG}_{4} \mathrm{~T}_{4}\right)$, which is more stable than $d\left(T_{4} G_{4} T_{4}\right)$. This conclusion also applies to the comparison of thermal stability of their tetraplexes, i.e., $\mathrm{d}\left(\mathrm{T}_{4} \mathrm{isoG}_{4} \mathrm{~T}_{4}\right)_{4}$ is more stable than $\mathrm{d}\left(\mathrm{T}_{4} \mathrm{G}_{4} \mathrm{~T}_{4}\right)_{4}$. Subsequently, in 1997 , they proved that the stability of $d\left(\mathrm{~T}_{4} \mathrm{isoG}_{4} \mathrm{~T}_{4}\right)$ against exonuclease hydrolysis is much higher than that of $d\left(T_{4} G_{4} T_{4}\right){ }^{119}$ The same is true for their tetraplexes. In general, base residues can pair to cause reverse trimerization or tetramerization, but when the increasing energy arising from stacking or hydrogen bonding is greater than the energy lost because of the main degeneration, the double helix structure is generally more stable, and still able to maintain a stable Watson-Crick base pair model.

In 1997, by native polyacrylamide gel electrophoresis (PAGE), Roberts $^{\mathbf{1 4 1}}$ et al. reported that similar to $\mathrm{G}$, isoG also shows a tendency to form tetraplexes, showing the similar monomer, dimer, tetramer structure (Fig. 18a-f). Notably, they found that isoG can even form mixed quartets with $\mathrm{G}$, which may induce the formation of mixed tetraplexes. Moreover, isoG-tetraplex may show higher stability than G-tetraplex in the presence of $\mathrm{K}^{+}$. And isoG-tetraplex shows a preference for $\mathrm{K}^{+}$over $\mathrm{Na}^{+}$. Afterwards, in 1998, Seela ${ }^{98}$ et al. concluded that oligonucleotide tetraplex $\mathrm{d}\left(\mathrm{T}_{4} \mathrm{isoG}_{4} \mathrm{~T}_{4}\right)_{4}$ has an ion preference in the following order: $\mathrm{K}^{+}>\mathrm{Rb}^{+}>\mathrm{Cs}^{+}>\mathrm{Na}^{+}>\mathrm{Li}^{+}$. In contrast, the order for
$\mathrm{d}\left(\mathrm{T}_{4} \mathrm{G}_{4} \mathrm{~T}_{4}\right)_{4}$ is $\mathrm{K}^{+}>\mathrm{Rb}^{+}>\mathrm{Na}^{+}>\mathrm{Cs}^{+}>\mathrm{Li}^{+}$. In 1999, Switzer ${ }^{115}$ et al . reported that ionic identity can determine the self-assembly of DNA strands into quadruplexes or pentaplexes. In the presence of $\mathrm{Cs}^{+}$, isoG self-assembles into pentaplexes. Whereas, in the presence of $\mathrm{Na}^{+}$and $\mathrm{K}^{+}$, it forms quadruplexes. However, it was found that $\mathrm{G}$ self-assembles into almost the same quadruplexes in $\mathrm{Cs}^{+}$and $\mathrm{K}^{+}$, which is consistent with the results of $\mathrm{Sen}^{\mathbf{1 4 2}}$ et al. in 1993. Interestingly, in 2001, Seela ${ }^{143}$ et al. found that 8-aza-7deaza-isoG $\mathrm{d}_{\mathrm{d}}$ (43a, Fig. 10) can self-assemble into $\mathrm{d}\left(\mathrm{T}_{4}(\mathbf{4 3 a})_{4} \mathrm{~T}_{2}\right)$. And the compound 43a can form a pentaplex (Fig. 18g) in the presence of $\mathrm{Cs}^{+}$, and a tetraplex in the presence of $\mathrm{Na}^{+}, \mathrm{K}^{+}$and $\mathrm{Rb}^{+}$. This is different from $d\left(\mathrm{~T}_{4} \mathrm{isoG}_{4} \mathrm{~T}_{2}\right)$ because the $d\left(\mathrm{~T}_{4^{-}}\right.$ isoG $_{4} \mathrm{~T}_{2}$ ) can self-assemble into both four-stranded and fivestranded structure in $\mathrm{Rb}^{+}$solution. In addition, in 1997, they reported that 7-deaza-isoG $\mathrm{d}_{\mathrm{d}}$ (44a, Fig. 10) can also form a tetraplex, identical in hydrogen-bonding structure to $d\left(\mathrm{~T}_{4} \text { isoG }_{4} \mathrm{~T}_{4}\right)_{4}$, but the former is less stable because of the heterocycle change. ${ }^{\mathbf{1 4 4}}$ This observation is also a confirmation that N7 does not participate in the isoG hydrogen-bonding system. Moreover, in 1997 , they proved that isoG $\mathrm{G}_{\mathrm{d}}$ is sensitive to acid and can be easily hydrolyzed under acidic conditions. ${ }^{\mathbf{1 4 4 - 1 4 6}}$ But 7-deaza and 8-aza-7-deaza purines can add to the stability of the glycosylic bond. Moreover, 7-deaza-isoG $\mathrm{d}_{\mathrm{d}}$ can form stronger tetraplexes in the presence of $\mathrm{Na}^{+} / \mathrm{K}^{+}$comparing to isoG ${ }_{\mathrm{d}}$, respectively. The 7halogen substitution is capable of enhancing stabilities of the base pairs (even in mismatches), glycosylic bond, and duplexes of 8-aza-7-deaza-isoG derivatives. However, 7-deaza-isoG ${ }_{d}$ show the topmost glycosylic bond stability but the lowest duplex stability. ${ }^{145}$

5.3.4 Parallel-stranded (ps) and antiparallel stranded (aps) chains containing isoG. A high $A_{d}-T_{d}$ content and the special sequences are prerequisites for ps DNA duplexes. ${ }^{147}$ In general, ps DNA is more unstable than the aps counterparts, because of weaker stacking interactions and hydrogen bonds by $A_{d}-T_{d}$ reversed Watson-Crick (Donohue) base pairing. $G$ and 5methyl-isoC base pair incorporated with A-T can lead to ps duplexes with lower stability than the corresponding aps duplexes (Fig. 19). ${ }^{148}$ Ps DNA can be found in some oligonucleotide duplexes, triplexes and some tetrameric aggregates. In 1993, Seela ${ }^{148-150}$ et al. initially reported that the oligonucleotides containing isoG-C can form a new type of ps DNA duplexes (Fig. 19). And then, in 1999, they proposed that if a central $A_{d}-T_{d}$ is replaced by a iso $\mathrm{G}_{\mathrm{d}}-\mathrm{C}_{\mathrm{d}}$, the stability of the original aps duplex will be reduced. ${ }^{151}$ Further, if isoG ${ }_{d}-C_{d}$ replaces two $A_{d}-T_{d}$ pairs, it will form the ps chains. However, oligonucleotides containing isoG $_{\mathrm{d}}-$ isoC $_{\mathrm{d}}$ still keep aps duplexes (Fig. 19). Notably, in 2013,

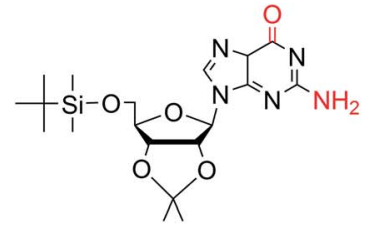

57

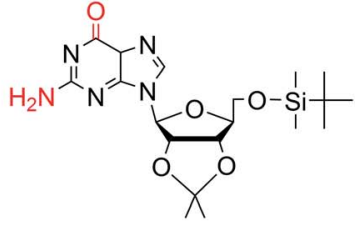

58

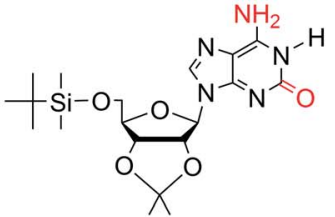

53

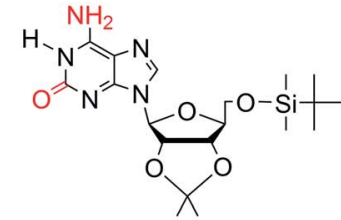

59

Fig. 17 The $D$ and $L$ structures of the protected $G$ and isoG. 

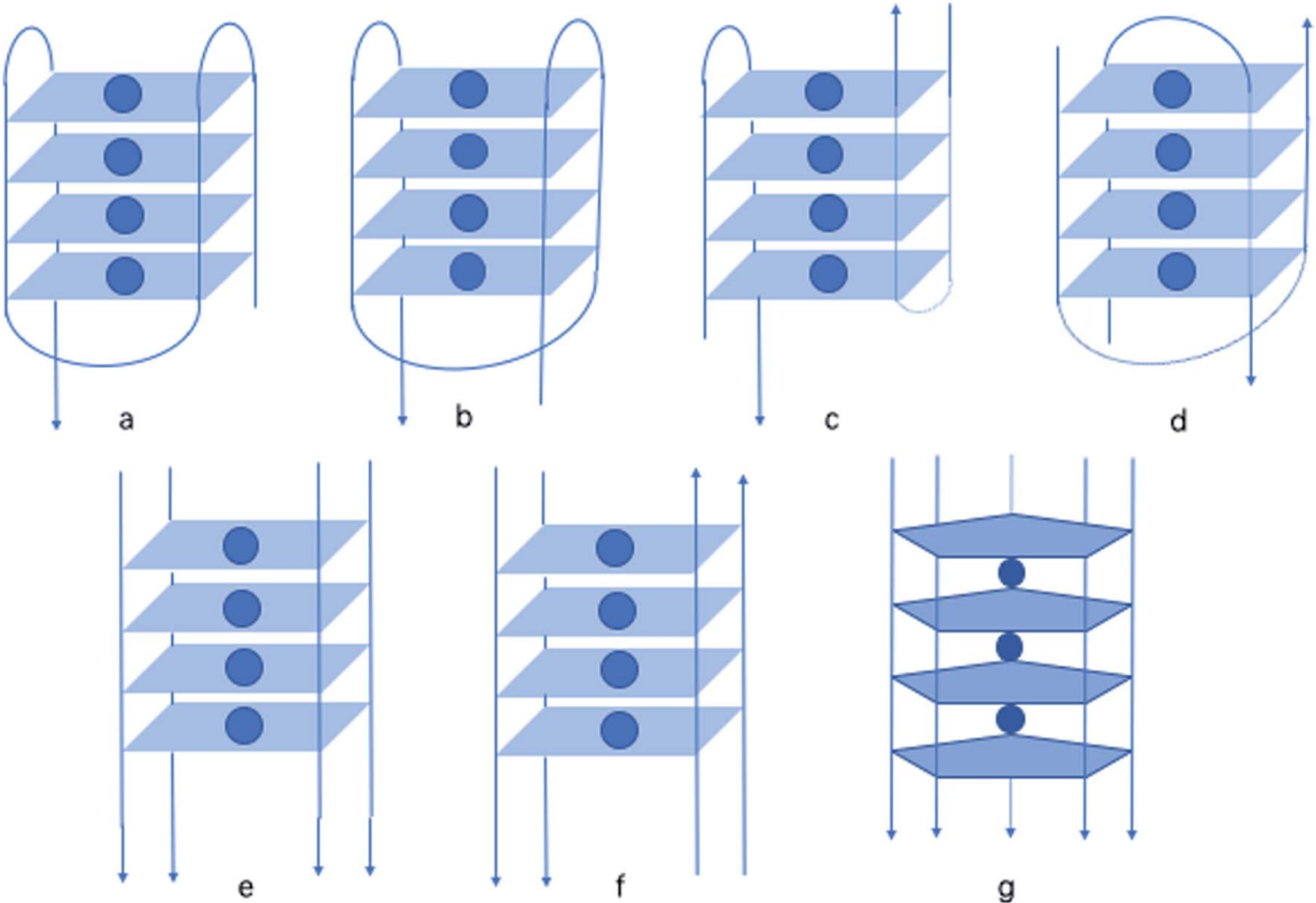

Fig. 18 A variety of oligonucleotide structures: (a) monomer chair, (b) monomer basket, (c) dimer chair, (d) dimer basket, (e) tetramer parallel, (f) tetramer antiparallel, (g) pentaplex.

\section{5'- $d$ ( T isoC A T A A isoC T G T A T ) - 3' 5'- $d\left(A \quad G \quad T A T T\right.$ G A C A T A ) $-3^{\prime}$}

\section{5'- $d(T$ isog A T A A isog T G T A T ) - 3' $5^{\prime}-\mathrm{d}(\mathrm{A} \quad \mathrm{C}$ T A T T $C$ A C A T A $)-3^{\prime}$}

\section{5'- $d$ ( T isoC A T A A isoC T G T A T ) - 3' $3^{\prime}-d\left(A\right.$ isog T A T T isog A C A T A ) $-5^{\prime}$}

Fig. 19 Ps duplexes with isoC-G/isoG-C and aps duplexes with isoCisoG.

they reported that tridentate iso $\mathrm{G}_{\mathrm{d}}-\mathrm{C}_{\mathrm{d}}$ base pairs can be used to compensate for the loss and stabilize ps DNA. ${ }^{152}$ In addition, in 2003, they proposed that 7-halogenated 8-aza-7-deaza-isoG $\mathrm{G}_{\mathrm{d}}$ (43b, 43c, Fig. 10) can significantly increase the duplex stability of 8-aza-7-deaza-isoG $\mathrm{d}_{\mathrm{d}}$ (43a) both in ps and aps DNA. ${ }^{67}$ In 2015 , they raised that ${ }^{F_{\text {isoG }}}$ (51b, Fig. 11) can add to the stability of aps duplexes, and this effect correlates to the number of incorporated ${ }^{F_{i s o G}}$ units. $^{78}$ But this is not true for ps duplexes because the sugar conformation of ${ }^{F_{i s o G}}$ does not apply to ps duplexes.

\section{Applications}

In the above parts, the discovery of isoG, its synthesis, modifications, tautomerism, and different mismatches, as well as the self-assembly properties of isoG, have been introduced. Based on the above characteristics, the applications of isoG have been investigated, such as the formation of supramolecular gels, the role of base-pairing in duplexes, its use as an ionophore, and its use as an antitumor agent. In the following sections, these applications will be discussed in detail.

\section{1 isoG-based supramolecular hydrogels}

Hydrogels have been an important topic for centuries because of their diverse applications in many fields, including in nanoscience, medicine, and the cosmetics industry. Hydrogels are viscoelastic solid-like materials composed of an elastic crosslinked network, and the major component solvent. ${ }^{153}$ Hydrogels can be divided into two categories. One is polymer hydrogels, whose shape is maintained by strong chemical bonds crosslinked long chains, which cannot be broken easily and are not thermally reversible. The other one is low molecular weight hydrogels (LMWH). LMWH formed by the self-assembly of materials through noncovalent interactions, such as hydrogen-bonding, $\pi-\pi$ stacking, hydrophobic forces, and van der Waals interactions. LMWH, also known as supramolecular hydrogels or physical hydrogels, will be discussed in this paper. Nucleosides are desirable candidates for building 
supramolecular hydrogels because of their ability to selfassemble via noncovalent interactions, as well as their biocompatibility in cells.

The gelation of guanylic acid was firstly identified in 1910 by Bang. ${ }^{154} \mathrm{G}$ and some of its derivatives can self-assemble into various supramolecular gels based on its unique hydrogen bond donors and receptors. ${ }^{\mathbf{1 5 4}}$ There have been many reports concerning G-based hydrogels and their applications in diagnostics and nanoscience. But these G-based hydrogels all show short lifespans. So finding new nucleosides that can form long-life supramolecular hydrogels is crucial. Like G, isoG can form gels as well. In a synthesis of isoG in 1951, Davoll ${ }^{7}$ noted the formation of a "gelatinous material" during the deamination of 2,6-diaminopurine, but he did not characterize this material further by biochemistry. It was preliminarily described that the aggregation state of nucleosides turns viscous at higher concentrations and when cooled. Then in 1965, Ravindranathan $^{40}$ et al. synthesized isoG and gave proof for the phenomenon observed by Davoll. ${ }^{7}$ They reported the formation of asymmetry, ruled, ordered, spiral and temperaturedepending structures where the nucleosides were uncharged. And these structures are similar to the gel formed by $5^{\prime}$ monophosphate-guanosine ( $5^{\prime}$-GMP), as identified by infrared spectroscopy. However, the preference of isoG for alkali ions is different from that of $\mathrm{G}$. They also concluded that the purine ring may be hydrogen-bonded with the amino group of another molecule, and the carbonyl group does not participate in the formation of the ordered structure.

As shown in Table 4 and Fig. 20, remarkably, in 2017, Seela ${ }^{155}$ et al. found that isoG-based hydrogels formed in various solutions containing $\mathrm{Li}^{+}, \mathrm{Na}^{+}, \mathrm{K}^{+}, \mathrm{Rb}^{+}$and $\mathrm{Cs}^{+}$, but not in water. And all hydrogels present significant longer lifespans (two or three months) compared to those of $\mathrm{G}$ (several days), as well as higher thermodynamic stability and wider $\mathrm{pH}$ range. The rheological results suggested that the stabilities of isoG-based gels are strikingly higher than those of G. And scanning electronic microscope (SEM) images revealed that isoG-based hydrogels form helix-like cylinders, whereas G-based gels form individual flat ribbons. As reported, hydrogels formed by isoG at

Table 4 The property of supramolecular gel forming by isoG, its derivatives and $\mathrm{G}$-iso $\mathrm{G}$ co-gel

\begin{tabular}{|c|c|c|c|c|c|c|}
\hline & $\mathrm{H}_{2} \mathrm{O}$ & $\mathrm{Li}^{+}$ & $\mathrm{Na}^{+}$ & $\mathrm{K}^{+}$ & $\mathrm{Rb}^{+}$ & $\mathrm{Cs}^{+}$ \\
\hline isoG & $\mathrm{S}^{c}$ & Gel & Gel & Gel & Gel & Gel \\
\hline G & $-^{e}$ & $\mathrm{Cry}^{b}$ & $\mathrm{Cry}^{b}$ & Gel & $\mathrm{Cry}^{b}$ & Cry \\
\hline isoG $_{\mathrm{d}}$ & Gel & Gel & $\mathrm{S}^{c}$ & Gel & Gel & $\mathrm{S}^{c}$ \\
\hline $\mathrm{G}_{\mathrm{d}}$ & Cry $^{b}$ & $\mathrm{Cry}^{b}$ & Cry $^{b}$ & Gel & $\mathrm{VS}^{d}$ & Cry $^{b}$ \\
\hline FisoG $_{\mathrm{d}}$ & Gel & Gel & Gel & Gel & Gel & $\mathrm{S}^{c}$ \\
\hline $\mathrm{z}^{8}$ isoG $_{\mathrm{d}}$ & Pre $^{a}$ & Pre $^{a}$ & Pre $^{a}$ & Gel & Pre $^{a}$ & Pre $^{a}$ \\
\hline $\mathrm{z}^{8} \mathrm{G}_{\mathrm{d}}$ & Pre $^{a}$ & $\mathrm{~S}^{c}$ & $\mathrm{~S}^{c}$ & $S^{c}$ & $S^{c}$ & $S^{c}$ \\
\hline $\mathrm{G}:$ isoG $(1: 1)$ & $-^{e}$ & $\operatorname{Pre}^{a}$ & $\mathrm{Cry}^{b}$ & Gel & Gel & Cry \\
\hline $\mathrm{G}:$ isoG $(1: 3)$ & $-^{e}$ & $\mathrm{Cry}^{b}$ & $\mathrm{Cry}^{b}$ & Gel & Gel & Cry \\
\hline $\mathrm{G}:$ isoG $(3: 1)$ & $-^{e}$ & $\mathrm{Cry}^{b}$ & Cry $^{b}$ & Gel & $\mathrm{Cry}^{b}$ & Cry \\
\hline
\end{tabular}

physiological $\mathrm{Na}^{+}$concentration showed a good small molecule loading and releasing capacity in phosphate buffered saline (PBS) buffer. This suggested their potential applications in drug delivery and as ionophores carrying different ions. In addition, supramolecular hydrogel systems of isoG $\mathrm{d}_{\mathrm{d}}$ (51a, Fig. 11) solutions containing $\mathrm{Li}^{+}, \mathrm{K}^{+}$and $\mathrm{Rb}^{+}$have been established. However, in $\mathrm{Na}^{+}$and $\mathrm{Cs}^{+}$solutions, these hydrogels can not take shape. Moreover, the derivative ${ }^{F_{i s o G}}$ (51b, Fig. 11) can also form supramolecular hydrogels in the presence of $\mathrm{Li}^{+}, \mathrm{Na}^{+}, \mathrm{K}^{+}$ and $\mathrm{Rb}^{+}$. While in solutions containing $\mathrm{Cs}^{+}$, precipitates form, indicating the ion dependence of the three nucleosides-based gels is different.

Hydrogels with fluorescence have aroused much attention due to its latent applications in drug delivery, molecule marking, and tissue engineering. As discussed before, $\mathrm{z}^{8}$ isoG $_{\mathrm{d}}$, $\mathrm{z}^{8} \mathrm{G}_{\mathrm{d}}$ are virtually fluorescent in alkaline environment and at neutral pH, similar to those reported for 8-aza-G and relevant 8azapurine nucleosides. ${ }^{70-73}$ Notably, iso $G_{d}$ and $G_{d}$ are not fluorescent. In addition, $z^{8}$ isoG $_{d}$ and $z^{8} G_{d}$ both show self-assembly properties. So experiments have been carried out by Seela ${ }^{156}$ et al. in 2017 to prepare smart (stimulus-responsive) gels with fluorescence, which can be regulated by external changes, such as $\mathrm{pH}$, heat and nucleoside mimics. Remarkably, $\mathrm{z}^{8}$ isoG $_{\mathrm{d}}$ formed the first G-similar hydrogel with fluorescence properties even in solid state. And the hydrogel also shows a longer lifetime and higher thermal stability than isoG and $G$ hydrogels. However, $z^{8} G_{d}$ does not form a gel under experimental conditions. $\mathrm{z}^{8}$ isoG $_{\mathrm{d}}$ hydrogel has a great selectivity for $\mathrm{K}^{+}$, and its pentad and tetrad structures are the basis of its self-assembly into gels. SEM images revealed that $\mathrm{z}^{8}$ isoG $_{\mathrm{d}}$ gel forms dense fibers and bundles, whereas $z^{8} G_{d}$ forms nanotubes. It makes great significance that the fluorescence hydrogel formed by $\mathrm{z}^{8}$ isoG $_{\mathrm{d}}$ can take response to external changes such as $\mathrm{pH}, \mathrm{UV}$, and heat. Additionally, in terms of the ability to form gels even at a very low $\mathrm{KCl}$ concentrations, $\mathrm{z}^{8}$ isoG $\mathrm{G}_{\mathrm{d}}$ hydrogel is expected to be applied in various fields of nanobiotechnology, chemistry, biology and medicine. Interestingly, although N7 does not participate in the isoG hydrogen-bonding system, the absence of N7 in 7-deaza-isoG $\mathrm{d}_{\mathrm{d}}$ results in this system being unable to form a hydrogel. Moreover, the addition of 1.0 equivalent of 7deaza-isoG $\mathrm{G}_{\mathrm{d}}$ can break the hydrogels formed by isoG and the fluorescence hydrogels formed by $\mathrm{z}^{8}$ isoG $_{\mathrm{d}}$.

Self-healing is an ability to self-repair when the external stimuli, such as $\mathrm{pH}$, external force and temperature, are moved. It is one of the most attractive properties of hydrogels and empowers them with diverse applications in many fields like tissue engineering. For example, so-called injectable hydrogels undergo shear-thinning on injection, but the hydrogels recover soon after injection. ${ }^{157}$ There have been many reports on selfhealing polymer hydrogels, but only a few studies concerning the self-healing supramolecular nucleoside hydrogels have been published. In 2018, Das ${ }^{158}$ et al. developed a self-healing arylboronate esters mediated G-quartet hydrogel as promising 3D-bioink. However, the applications of G-based hydrogels are limited for their short lifetime within hours and low stabilities. This has drawn attention to isoG, an isomer of G. However, the injection of isoG hydrogels is challenging. ${ }^{159}$ Recently, inspired 


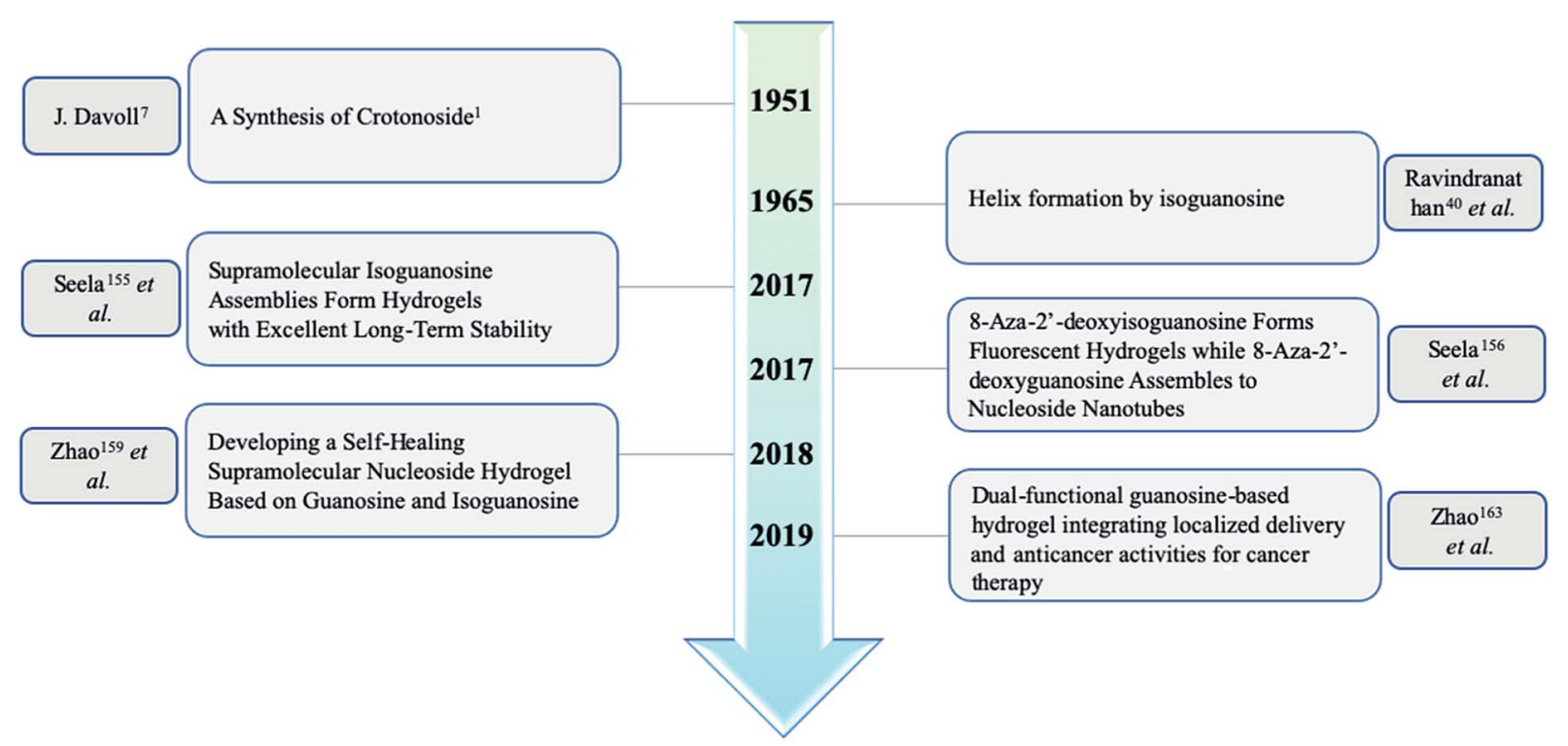

Fig. 20 The development of hydrogels formed by isoG.

by the self-assembled tetramers formed by mixing $d\left(T_{4} G_{4} T_{4}\right)$ and $\mathrm{d}\left(\mathrm{T}_{4} \mathrm{isoG}_{4} \mathrm{~T}_{4}\right)$ verified by Seela ${ }^{140}$ et al. in 1996, the tetraplexes formed by $\mathrm{d}\left(\mathrm{T}_{8} \mathrm{isoG}_{4} \mathrm{~T}\right)$ and $\mathrm{d}\left(\mathrm{T}_{4} \mathrm{G}_{4} \mathrm{~T}\right)$ in the presence of $\mathrm{K}^{+}$ proved by Roberts ${ }^{141}$ et al. in 1997, and the self-healing co-gel developed by mixing $\mathrm{G}$ and $\mathrm{G}_{\mathrm{d}}$ by Adhikari ${ }^{160}$ et al. in 2014, Zhao $^{159}$ et al. successfully constructed a self-healing supramolecular co-hydrogel in 2018 by simply mixing G and isoG with $1: 1$ and $1: 3$ molar ratios in the presence of $\mathrm{K}^{+}$. In terms of ion dependence, both mixtures can form co-gels in the presence of $\mathrm{K}^{+}$and $\mathrm{Rb}^{+}$. But the $3: 1$ could only produce a co-gel in the presence of $\mathrm{K}^{+}$. Furthermore, the lifespan of the gels varied from hours to months. SEM images show that these co-gels form flower-like structures. Rheological and injection experiments concluded the excellent self-healing properties, short recovery time, and syringeability of the co-gel. Moreover, $\mathrm{G}_{2} \mathrm{isoG}_{2}$-quartets are possibly formed inside the self-healing supramolecular nucleoside co-gel.

Furthermore, it is widely known that isoG possesses antitumor property toward several cancer lines (details are shown in Section 6.5); $;^{58,161}$ and the injectable property could greatly promote the application of these supramolecular gels in antitumor treatment. In addition, borate ester is well-known as a dynamic covalent bond to construct self-healing hydrogels. Based on these, in 2017, Sadler ${ }^{162}$ et al. developed an anticancer hydrogel (dopamine-conjugated platinum $\mathrm{IV}_{-} \mathrm{G}_{4} \mathrm{~K}^{+}$-borate ester, $\mathrm{Pt}_{-} \mathrm{G}_{4} \mathrm{~K}^{+} \mathrm{B}$ hydrogel) by using borate ester linkage. Inspired by above-mentioned findings, recently, $\mathrm{Zhao}^{163}$ et al. developed another type of dual-functional co-gel called isoguanosineborate-guanosine (isoGBG) hydrogel (Fig. 21), which possesses delivery and antitumor activities. isoGBG hydrogel displays excellent stability, self-healing property and biocompatibility, as well as highly antitumor activity and excellent inhibition of tumor recurrence in vivo. Moreover, the mechanism was preliminarily explored, and it was concluded that the mechanism of inhibiting oral cancer cells might be through the caspase-dependent signaling pathway to induce apoptosis via regulating dephosphorylation of epidermal growth factor receptor (EGFR) (Fig. 21).

\subsection{Applications of isoG mispairing}

In Section 5.2, different mismatches and the incorporation of isoguanine have been discussed. Although isoG can be integrated into DNA/RNA by multiple enzymes in various templates, isoG-isoC is not accepted as a natural base pair. The three reasons why isoG-isoC cannot be a natural base pair are: (1) tautomerism causes unstable base pairing; ${ }^{96,101}$ (2) deoxygenated isoC is easily degraded to deoxygenated $\mathrm{U}^{101}$ (3) isoG-isoC cannot form an R-type triple-chain structure. ${ }^{164}$ Although the tautomerism of isoG limits its stable transmission as a gene letter, it enables the existence of gene mismatch, suggesting isoG's various alternative applications. In 1996, for the first time, Kamiya ${ }^{103}$ et al. suggested that isoG may be mutagenic and lead to A to C, A to $\mathrm{G}$ and A to $\mathrm{T}$ transversions in cells. Then in 1997 , isoG is proved to induce mutagenicity in $E$. coli, ${ }^{32}$ as well as in living COS-7 cells, ${ }^{165}$ but it does not hinder the replication. These indicate the mutation caused by isoG can occur in both eukaryotic and prokaryotic cells. Interestingly, the mutagenicity is affected by the sequence and strands that the base is located in. 8-OH-dGTP is a significant marker of DNA oxidation. In 1998, Kamiya ${ }^{166}$ et al. demonstrated that the mutagenicity induced by 2-OH-dATP in E. coli was more significant than that caused by $8-\mathrm{OH}-\mathrm{dGTP}$, which also gave a confirmation of 2-OHdATP-G base pair.

Interestingly, the nonstandard isoG-isoC base pair contributes to the stability of duplexes. In 2001, Turner ${ }^{97}$ et al. reported this effect has a sequence dependency in duplexes because of the large difference in electron density. In 2004, Prudent ${ }^{167,168}$ et al. proved that isoG-isoC stabilizes the G-C double helix and can be applied to polymerase chain reaction (PCR) to detect the 

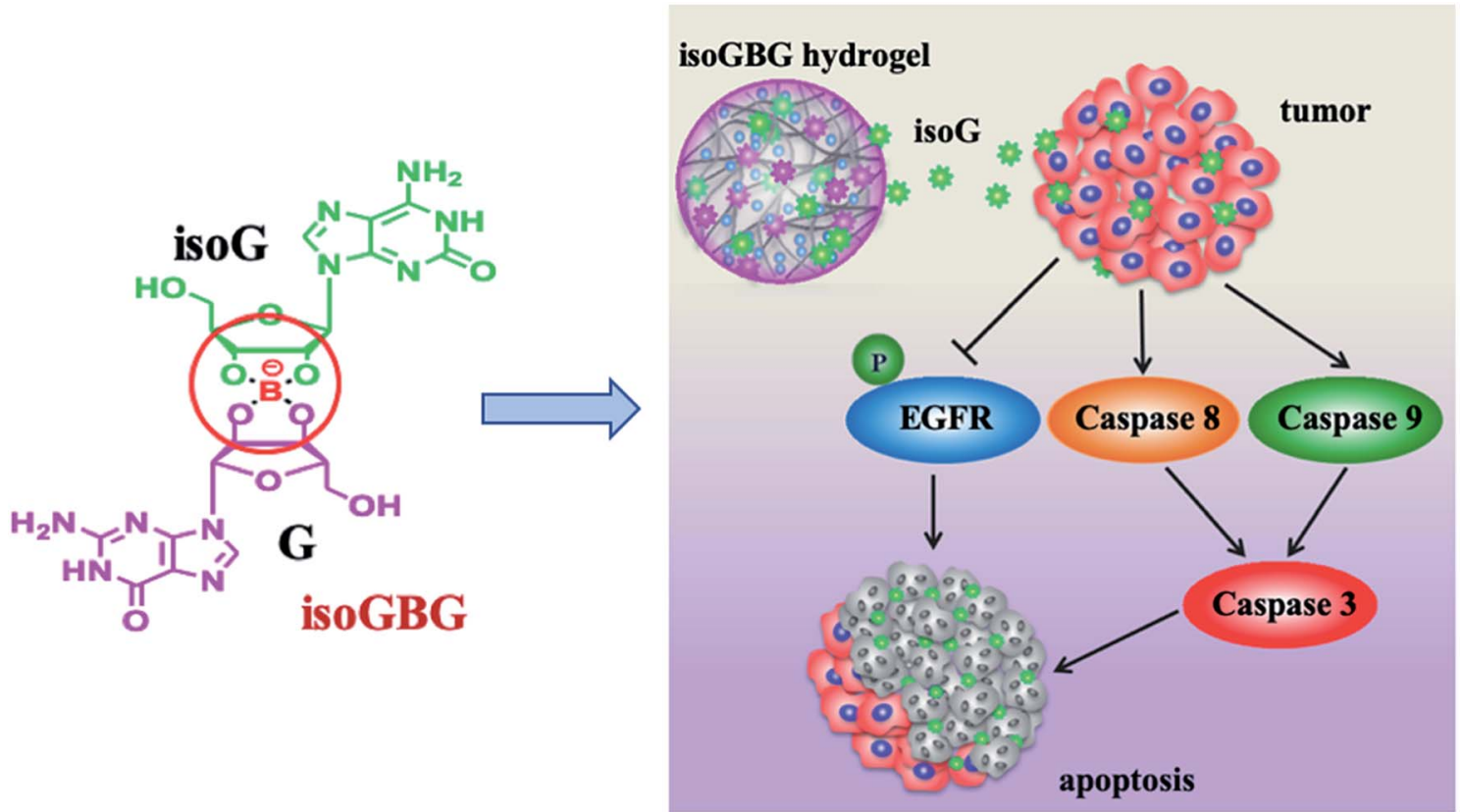

Fig. 21 The dual-functional isoGBG displays antitumor activity, may via the caspase-dependent signaling pathway to induce apoptosis via regulating dephosphorylation of EGFR.

mutant genes. Beyond that, in 1992, Benner ${ }^{169}$ et al. raised that it can help regulate ribosome translation. $91 \%$ of isoGcontaining RNA could be read, which is higher than the control, because the frameshift with isoG skips the isoC. However, the transfer RNA (tRNA) containing the meaningless CUA codon is meaningless and results in translation termination. This property can also aid the development of nonstandard base pairs to extend gene dictionaries and provide a deeper understanding of translation termination. Moreover, in 1993, Switzer ${ }^{101}$ et al. reported that the tautomerism of isoG leads to various mispairings, which may enhance the antiviral activity. The stability of base-pairs of $z^{8}$ isoG ${ }_{d}$ (46, Fig. 10) with 5-methylisoC, $A_{d}, T_{d}, C_{d}$ and $G_{d}$ can be monitored by fluorescence, ${ }^{73}$ in other words, the fluorescence signal is correlated with DNA base paring stability. Thus, $\mathrm{z}^{8}$ isoG $\mathrm{G}_{\mathrm{d}}$ can be applied as a sensor with fluorescence for detecting mismatch DNA duplexes, even more complicated DNA structures,${ }^{73}$ such as in triplexes reported by Seela ${ }^{170}$ et al. in 2010.

\subsection{Applications of 1-methyl-isoG}

In 1981, Fuhrman ${ }^{171}$ et al. reported that isoG presents negative inotropic and chronotropic effects in the myocardium. And those effects can be antagonized by theophylline. The effects of negative inotropic and chronotropic activity ranked in the order isoG $>1$-methyl-isoG > adenosine $>2$-methoxyadenosine. And these substances may act on the same receptor. In addition, as reported by Emerson ${ }^{172}$ et al. in 1949 and Brown ${ }^{173}$ et al. in 1952, isoG can produce smooth muscle relaxation, hypotension and bradycardia effects that are more potent and longer-lasting than those of adenosine. Remarkably, 1-methyl-isoG (37, Fig. 10) was also found to have muscle relaxation, hypothermia, hypotension, anti-inflammatory, activating adenosine cyclase (AC) and anti-allergic effects (Fig. 22). . $^{30,50,51,56,174-177}$ In 1981, as shown in Table 5, a comparison of effects of the derivatives of 1methyl-isoG have been explored by $\mathrm{Cook}^{56} \mathrm{et}$ al. Moreover, the effects of halogenated analog 2-chloroadenosine are greater. ${ }^{30}$

These effects induced by 1-methyl-isoG are more potent than adenosine because 1-methyl-isoG can resist the action of adenosine deaminase. So 1-methyl-isoG can exist in the extracellular fluid for a long time, whereas adenosine has been degraded into inactive inosine..$^{51}$ And there is a positive correlation between the potency of resistance to adenosine deaminase and the muscle relaxation and cardiovascular effects. ${ }^{30,51,178}$ However, in 1985, Radulovacki ${ }^{179}$ et al. reported 1methyl-isoG does not have a strong hypnosis effect similar to

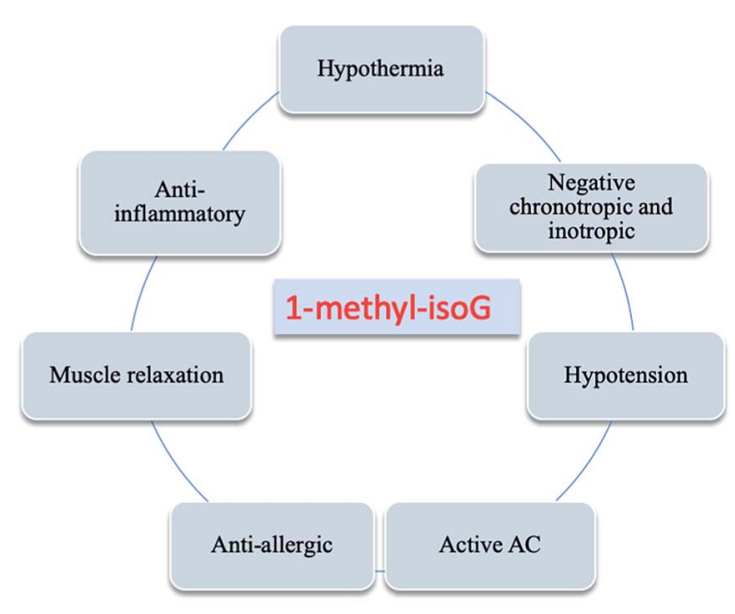

Fig. 22 Effects of 1-methyl-isoG. 
Table 5 Comparisons of the effectiveness of 1-methyl-isoG and its derivatives in muscle relaxation, hypothermia, hypertension, anti-inflammatory and antiallergy effects

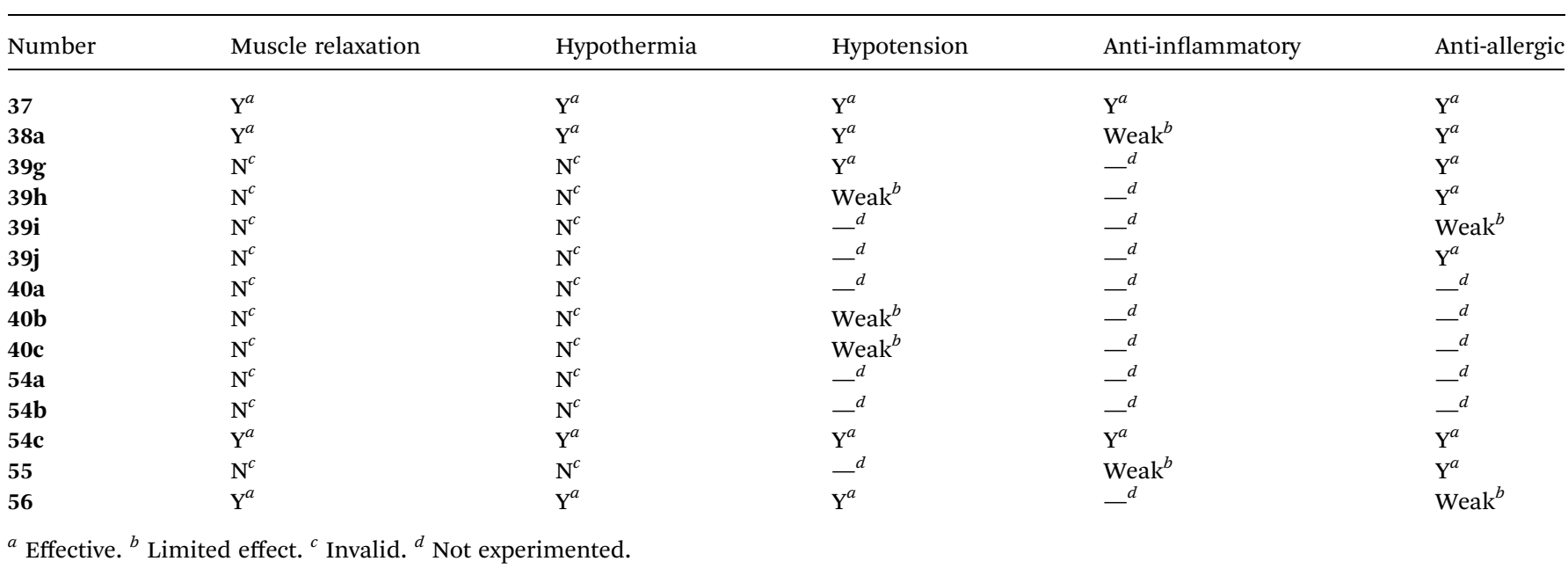

adenosine. And, in 1981, Spence ${ }^{180}$ et al. showed that the effects of 1-methyl-isoG and adenosine on neuromuscular transmission in the vas deferens are similar. This is probably because the enzyme activity of adenosine deaminase in the vas deferens is inherently low, and thus the degradation is low. The ability of 1-methyl-isoG to cause the accumulation of cyclic adenosine monophosphate (cAMP) in brain is not effective as that of adenosine, ${ }^{\mathbf{1 8 1}}$ but neither of these two nucleosides show inhibition of rat brain cAMP phosphodiesterase (PDE). Besides, in 1980, Taylor $^{30}$ et al. proved that accumulated adenylate cyclase (AC) caused by 1-methyl-isoG may be associated with cardiovascular/relaxation effects.

In 1981, Marwood ${ }^{177}$ et al. showed that 1-methyl-isoG has equal negative inotropic and chronotropic effects in guinea-pig isolated atria. Nevertheless, adenosine has a greater negative inotropic effect. The active site of 1-methyl-isoG is only on the atria, whereas adenosine can also act on ventricle. ${ }^{51}$ Furthermore, 1-methyl-isoG showed a biphasic response on cardiac output, which means a slow increase followed by a rapid initial decrease. ${ }^{177}$ The impact of 1-methyl-isoG in lowering response electrical stimulation in isolated perfused rat tail arteries is similar to that of adenosine. In 1980, Jamieson ${ }^{\mathbf{1 7 8}}$ et al. demonstrated that 1-methyl-isoG shows an inhibition of nervemediated stimulation, which is induced by electricity or nicotine in isolated guinea-pig ileum. But it is not useful for acetylcholine (ACh) and histamine-mediated contraction. Moreover, the site of action is at the post ganglionic nerve terminals because the effect disappears in isolated mammalian motor axons. Further, in 1981, Spence ${ }^{176}$ et al. demonstrated that the inhibitory dose for central excitation and monosynaptic or polysynaptic spinal reflex in conscious animals (central pathways) is much lower than that of neuromuscular junction. This means that muscle relaxation may be related to the central pathway (probably the spinal pathway).

In 1980, Taylor ${ }^{182}$ et al. reported 1-methyl-isoG does not compete with adenosine for uptake sites to activate adenosine cyclase. This indicates that it does not attenuate the effect of adenosine by competition, but because 1-methyl-isoG is not degraded and remains for a long time in the extracellular fluid. 1-Methyl-isoG was thought to act on a benzodiazepine receptor, but that the hypnotic effect was not the same as benzodiazepine ruled that out by Hall ${ }^{183}$ et al. in 1987. Those effects above are dose-dependent. ${ }^{30,51,176}$ And theophylline, a widely-used blocker of adenosine receptors, also acts as a dose-dependent antagonist of the effects of 1-methyl-isoG..$^{51,178,179}$ So 1-methyl-isoG may act on the same receptor as adenosine in the intestinal smooth muscle and pig brain.

\subsection{Ionophores}

Nuclear waste remnants from the Second World War, nuclear testing, and the nuclear industry have left a large amount of radioactive contamination, mostly $\mathrm{Cs}^{+}$and $\mathrm{Ra}^{2+}$. They are challenging to remove, leaving behind huge potential risk for human being and pollution of water and soil. Compounds that are highly selective for $\mathrm{Cs}^{+}$are required because of the large quantity of $\mathrm{Na}^{+}$and $\mathrm{K}^{+}$in nuclear waste. In 1990s, crown ethers have been developed to bind $\mathrm{Cs}^{+}$by $\mathrm{McDowell}^{\mathbf{1 8 4}}$ et al. and Sachleben ${ }^{185-188}$ et al. But the $\mathrm{Cs}^{+}$selectivity are modest resulting from their flexibility. So rigid macrocycles, especially calixarene crowns and their derivatives with different binding groups attached, have been used as recycling ligands. Rigid macrocycles show better complexation and selectivity for $\mathrm{Cs}^{+}$over other ions such as $\mathrm{Li}^{+}, \mathrm{Na}^{+}, \mathrm{K}^{+}$and $\mathrm{Rb}^{+}{ }^{189}$ In addition, in 1995, calixarene carriers were reported to have rattling cell membrane penetration in polymer inclusion membrane (PIMs) by Reinhoudt $^{\mathbf{1 9 0}}$ et al. However, these macrocycles are expensive to synthesize and the ionophore recovery, as well as cations release, are difficult. Nowadays, noncovalent ionophores containing isoG are widely used. They show greater affinity and selectivity for $\mathrm{Cs}^{+}$compared to those of calixarene and its derivatives. In 1997, Davis ${ }^{189}$ et al. reported the self-assembled (isoG) $)_{10} \cdot \mathrm{M}^{+}$ionophore shows significant selectivity for $\mathrm{Cs}^{+}$in 
competition experiments. And (isoG) $)_{10} \cdot \mathbf{M}^{+}$can even extract bound $\mathrm{Cs}^{+}$from a calixarene crowns ether. Thus, these compounds can be used for purification and metal nuclear waste disposal.

Further, in 2000, Davis ${ }^{80}$ et al. then reported that in the (isoG) $)_{10} \cdot \mathrm{Cs}^{+}$system (Fig. 15 and 16 ), $\mathrm{Cs}^{+}$and the protected isoG 53 are in constant exchange with the outside world. However, the exchange rate of $\mathrm{Cs}^{+}$itself is 40000 times faster than the compound 53, as shown by multinuclear NMR spectroscopy. So the ion carrier does not disintegrate during ion exchange. The ions can be easily dissociated from the noncovalent ionophore when the solvent polarity changes. The same exchange process is true for other metal ions. Specially, $\mathrm{Cs}^{+}$possesses an advantage that it can even slow down the isoG exchange rate. In 2001, they proved that the protected isoG 53 assembly can not only release $\mathrm{Cs}^{+}$more easily without dissociation, but also show a stronger affinity for larger cations such as $\mathrm{Cs}^{+}$and $\mathrm{Ba}^{2+}$ than $\mathrm{K}^{+}, \mathrm{Sr}^{2+}$ and $\mathrm{Na}^{+} \cdot{ }^{191}$ They also demonstrated that $(53)_{10} \cdot \mathrm{Cs}^{+}$can also promote selective transport through organic polymer inclusion membrane (PIMs) and bulk liquid membranes (BIMs), with high transport rates and excellent selectivity for $\mathrm{Cs}^{+}$. This cation-binding selectivity is attributed to the geometric hydrogen-bonding mode composed of donors and receptors. As discussed earlier, G forms G-quartets, whereas isoG prefers the formation of pentads. The sizes of these macrocyclic cavities of self-assembled ionophores determine the cation-binding selectivity. Moreover, in 2004, they reported that in the case of $\mathrm{G}$, the selectivity for $\mathrm{Ra}^{2+}$ prior to magnesium ion $\left(\mathrm{Mg}^{2+}\right)$ and calcium ion $\left(\mathrm{Ca}^{2+}\right)$ requires an existing lipophilic anion. ${ }^{192}$ Nevertheless, isoG shows preferential selectivity for $\mathrm{Cs}^{+}$over $\mathrm{Mg}^{2+}, \mathrm{Ca}^{2+}, \mathrm{Sr}^{2+}$ and $\mathrm{Ba}^{2+}$ without any additional environmental conditions. In addition, a significant radium ion $\left({ }^{226} \mathrm{Ra}^{2+}\right)$ preference over other monovalent alkali cations was observed for both $\mathbf{5 7}$ and 53, with a "precipitation prevention/ dissolving" property over a wide $\mathrm{pH}$ range. And, in 2005, Reinhoudt ${ }^{193}$ et al. reported that $\mathrm{Ra}^{2+}$ can be selectively extracted from gas-field produced water by isoG-based self-assemblies.

\subsection{Antitumor activity}

In $1994, \mathrm{Kim}^{\mathbf{1 6 1}}$ et al. found that isoG has strong anti-cancer effects against P338, L5178Y, Sp2/O, HL60, Lymphoma Raji, both in vitro and in vivo. And isoG shows especial effectiveness against ascites tumor and malignant solid tumor. It is generally believed that isoG enters the cell by simple diffusion or diffusion combined with active transporters. The phosphorylation of isoG in the cytoplasm produces active nucleotides that inhibit tumor growth. Moreover, in 1994, they also reported that most of 6-substituted isoG derivatives (42, Fig. 10) show low cytotoxicity against cancerous Pogras 1, HeLa and Molt-4 cells, except those with amino, sulfur and furfurylamine substituents. $^{58}$ This suggests that high cytotoxicity depends on the $\mathrm{N} 2 \mathrm{H}$ or $\mathrm{SH}$ perssad at $\mathrm{C6}$ position on the heterocyclic ring. In particular, when these substituents are displaced by nonpolar alkyl groups, the cytotoxicity decreases. Then in 1995, they demonstrated that the combination of berberine with isoG monophosphate greatly increases the antitumor effect. ${ }^{194}$
However, in 2004, Nowak ${ }^{\mathbf{1 9 5}}$ et al. reported that similar to other telomerase inhibitors, iso $_{\mathrm{d}}$ showed low potency and specificity in inhibiting tumor cell growth.

\subsection{More applications}

Apart from applications in gel formation, ionophore, and as antitumor agent, in 1973, isoG was reported to be an inhibitor of inosine monophosphate (IMP) pyrophosphorylase by Hagen. ${ }^{196}$ And in 1974 , Holy ${ }^{197}$ et al. reported that isoG can also inhibit inducible $E$. coli binding site. In addition, in 1975, Mantsch ${ }^{41}$ et al. reported that its 5'-di- and -tri-phosphates can strongly bind and inhibit glutamic acid dehydrogenase. In 1988, Wissler ${ }^{198}$ et al. reported that isoG also acts as an essential constituent of $\mathrm{Cu}(\mathrm{II})$-containing ribonucleic acid produced by cultured pig macrophages. This unusual $\mathrm{Cu}(\mathrm{II})$-containing extracellular RNA was a formidable angiogenesis factor, and acted as an adenosine A1-receptor agonist. Besides, in 1999, Davis $^{\mathbf{1 3 1}}$ et al. raised that the protected isoG (53, Fig. 11) selfassembly can act as phase transfer catalysts. And in 2018, Anna $^{174}$ et al. proposed that by strongly affecting the highly ordered structure of the G-quartet in TBA, isoG greatly affects the anticoagulant activity of the thrombin binding aptamer (TBA).

\section{Summary and outlook}

In summary, since Fischer first synthesized isoguanine in 1897, there have been many reports focusing on the comparison of isoG with G. In this review, we have detailed the discovery, and synthesis of base- or sugar-modified derivatives of isoG, its monomer structure and aggregates, and the diverse applications of isoG/isoguanine. Since the yields of isoG/isoguanine in natural sources such as croton beans, butterfly wings and marine mollusk are too low, a series of synthetic methods of isoG/isoguanine by introducing functional groups to the heterocycle of G and AICA have been proposed. And various base- or sugar-modified derivatives have been synthesized or found in nature. Additionally, some unique properties of isoG and its derivatives including enol-keto tautomerism, mispairing, self assembly into tetramer (isoG 4 ), decamer (isoG ${ }_{10}$ ) and isoG $_{4}$ quadruplex, and fluorescence suggest its potential diverse applications in the formation of supramolecular hydrogels, in ps and aps duplexes and even triplexes, also in waste-collection as an ionophore. In addition, further applications such as antitumor activity, inhibition of IMP-pyrophosphorylase, and mutation-inducing have been talked about. As the structure and properties of isoG become better understood, there will be further studies and more applications will be identified. For example, because of its unique hydrogen bond acceptors and donors, isoG is expected to have a wider range of applications in the field of supramolecular self-assembly, the formation of hydrogel and ionophore. Additionally, isoG is most likely to play a significant role in genetic disease monitoring probes because of the variable nonstandard pairs caused by its tautomerism and its incorporation by different enzymes. Moreover, benefited from its antitumor ability and self-assembly properties, the 
preparation of supramolecular gels integrating antitumor activity and drug delivery appears extremely significative. Thus, isoG may play a significant role in the clinical treatment of various cancers and other therapies involving smooth muscle relaxation, hypotension, and bradycardia. In conclusion, the unique properties of isoG, such as its use in supramolecular assemblies, as a nonstandard base and a medicine with antitumor activity, will broaden its applications in diverse fields.

\section{Conflicts of interest}

There are no conflicts to declare.

\section{Acknowledgements}

This study is supported by the National Natural Science Foundations of China (81922020, 81970950, 81621062).

\section{References}

1 M. Chen, W. Lin, L. Hong, N. Ji and H. Zhao, BioMed Res. Int., 2019, 2019, DOI: 10.1155/2019/6258248.

2 J. T. Davis, Angew. Chem., Int. Ed., 2004, 43, 668-698.

3 E. Fischer, Ber. Dtsch. Chem. Ges., 1897, 30, 2226-2254.

4 E. Cherbuliez and K. Bernhard, Helv. Chim. Acta., 1932, 15, 464-471.

5 R. Purrmann, Justus Liebigs Ann. Chem., 1940, 544, 182-190.

6 F. A. Fuhrman, G. J. Fuhrman, R. J. Nachman and H. S. Mosher, Science, 1981, 212, 557-558.

7 J. Davoll, J. Am. Chem. Soc., 1951, 73, 3174-3176.

8 G. B. Brown, G. Levin and S. Murphy, Biochemistry, 1964, 3, 880-883.

9 C. B. Reese, Y. S. Sanghvi and R. Kuroda, J. Chem. Soc., Perkin Trans. 1, 1987, 1527-1531.

10 K. J. Divakar, M. Mottahedeh, C. B. Reese, Y. S. Sanghvi and K. A. D. Swift, J. Chem. Soc., Perkin Trans. 1, 1991, 4, 771774.

11 C. Ji-Wang, L. Horng-Yuh, H. Min and S. Fang-Jy, Tetrahedron Lett, 1987, 28, 2151-2154.

12 S. Tirumala and J. T. Davis, J. Am. Chem. Soc., 1997, 119, 2769-2776.

13 X. Shi, J. C. Fettinger, M. Cai and J. T. Davis, Angew. Chem., Int. Ed., 2000, 39, 3124-3127.

14 M. V. Buell and M. E. Perkins, J. Biol. Chem., 1927, 72, 745749.

15 J. R. Spies and N. L. Drake, J. Am. Chem. Soc., 1935, 57, 774.

16 J. R. Spies, J. Am. Chem. Soc., 1939, 61, 350-351.

17 R. Falconer, J. M. Gulland and L. F. Story, J. Am. Chem. Soc., 1939, 1784, DOI: 10.1039/jr9390001784.

18 G. R. Pettit, R. H. Ode, R. M. Coomes and S. L. Ode, Lloydia, 1976, 39, 363-367.

19 J. Davoll and B. A. Lowy, J. Am. Chem. Soc., 1951, 73, 16501655.

20 A. Bendich, G. B. Brown, F. S. Philips and J. B. Thiersch, J. Biol. Chem., 1950, 183, 267-277.

21 B. A. Lowy, J. Davoll and G. B. Brown, J. Biol. Chem., 1952, 197, 591-600.
22 S. Friedman and J. S. Gots, Arch. Biochem. Biophys., 1951, 32, 227-229.

23 Z. Nackerdien, K. S. Kasprzak, G. Rao, B. Halliwell and M. Dizdaroglu, Cancer Res., 1991, 5837-5842.

24 M. Dizdaroglu, Mutat. Res., 1992, 275, 331-342.

25 R. Olinski, T. Zastawny, J. Budzbon, J. Skokowski, W. Zegarski and M. Dizdaroglu, FEBS Lett., 1992, 309, 193-198.

26 P. Jaruga, T. H. Zastawny, J. Skokowski, M. Dizdaroglu and R. Olinski, FEBS Lett., 1994, 341, 59-64.

27 T. Mori, Y. Hori and M. Dizdaroglu, Int. J. Radiat. Biol., 1993, 64, 645-650.

28 P. Jaruga and M. Dizdaroglu, Nucleic Acids Res., 1996, 24, 1389-1394.

29 H. Kamiya and H. Kasai, J. Biol. Chem., 1995, 270, 1944619450.

30 J. Baird-Lambert, J. F. Marwood, L. P. Davies and K. M. Taylor, Life Sci., 1980, 26, 1069-1077.

31 H. Kamiya, T. Ueda, T. Ohgi, A. Matsukage and H. Kasai, Nucleic Acids Res., 1995, 23, 761-766.

32 H. Kamiya and H. Kasai, Nucleic Acids Res., 1997, 25, 304311.

33 H. Kamiya, Mutat. Res., Genet. Toxicol. Environ. Mutagen., 2010, 703, 32-36.

34 H. Kasai, Free Radicals Biol. Med., 2002, 33, 450-456.

35 S. Frelon, T. Douki and J. Cadet, Free Radical Res., 2002, 36, 499-508.

36 J. Cadet, T. Douki and J. L. Ravanat, Environ. Health Perspect., 1997, 105, 1034-1039.

37 J. Cadet, T. Douki, J.-L. Ravanat and J. Wagner, Bioanal. Rev., 2012, 4, 55-74.

38 A. Weimann, G. McLeod, T. Henriksen, V. Cejvanovic and H. E. Poulsen, Scand. J. Clin. Lab. Invest., 2019, 79, 1-8.

39 V. Nair and D. A. Young, J. Org. Chem., 1985, 50, 406-408.

40 R. V. Ravindranathan and H. T. Miles, Biochim. Biophys. Acta, 1965, 94, 603-606.

41 H. H. Mantsch, I. Goia, M. Kezdi, O. Barzu, M. Dansoreanu, G. Jebeleanu and N. G. Ty, Biochemistry, 1975, 14, 55935601.

42 J. A. Montgomery and K. Hewson, J. Org. Chem., 1968, 33, 432.

43 L. De Napoli, D. Montesarchio, G. Piccialli, C. Santacroce and M. Varra, J. Chem. Soc., Perkin Trans. 1, 1995, 15, 45-47.

44 Q. Cheng, J. Gu, K. R. Compaan and H. F. Schaefer, Chem.Eur. J., 2012, 18, 4877-4886.

45 A. Yamazaki, I. Kumashiro, T. Takenishi and M. Ikehara, Chem. Pharm. Bull., 1968, 16, 2172-2181.

46 A. Yamazaki, M. Okutsu and Y. Yamada, Nucleic Acids Res., 1976, 3, 251-260.

47 J. W. Chern, G. S. Lin, C. S. Chen and L. B. Townsend, J. Org. Chem., 1991, 56, 4213-4218.

48 L. De Napoli, A. Messere, D. Montesarchio, G. Piccialli and M. Varra, Nucleosides Nucleotides, 1997, 16, 183-191.

49 F. A. Fuhrman, G. J. Fuhrman and K. Deriemer, Biol. Bull., 1979, 156, 289-299.

50 R. J. Quinn, R. P. Gregson, A. F. Cook and R. T. Bartlett, Tetrahedron Lett., 1980, 21, 567-568. 
51 Y. H. Kim, R. J. Nachman, L. Pavelka, H. S. Mosher, F. A. Fuhrman and G. J. Fuhrman, J. Nat. Prod., 1981, 44, 206-214.

52 W. Bergmann and R. J. Feeney, J. Org. Chem., 1951, 16, 981987.

53 W. Bergmann and D. C. Burke, J. Org. Chem., 1955, 20, 1501-1506.

54 W. Bergmann and D. C. Burke, J. Org. Chem., 1956, 21, 226228.

55 P. Searle and T. Molinski, J. Nat. Prod., 1994, 57, 1452-1454.

56 R. T. Bartlett, A. F. Cook, M. J. Holman, W. W. McComas, E. F. Nowoswait, M. S. Poonian, J. A. Baird-Lambert, B. A. Baldo and J. F. Marwood, J. Med. Chem., 1981, 24, 947-954.

57 D. Firsova, K. Calabro, P. Lasserre, F. Reyes and O. P. Thomas, Tetrahedron Lett., 2017, 58, 4652-4654.

58 S. Lee, J. Kim, Y. Cho and J. Kim, Arch. Pharmacal Res., 1994, 17, 170-174.

59 C. Buhr, R. Wagner, D. Grant and B. Froehler, Nucleic Acids Res., 1996, 24, 2974-2980.

60 G. Balow, V. Mohan, E. A. Lesnik, J. F. Johnston, B. P. Monia and O. L. Acevedo, Nucleic Acids Res., 1998, 26, 3350-3357.

61 F. Seela and H. Thomas, Helv. Chim. Acta, 1995, 78, 94-108.

62 N. Ramzaeva and F. Seela, Helv. Chim. Acta, 1996, 79, 15491558.

63 F. Seela and Y. Chen, Chem. Commun., 1996, 2263-2264, DOI: 10.1039/CC9960002263.

64 G. Becher, J. He and F. Seela, Helv. Chim. Acta, 2001, 84, 1048-1065.

65 F. Seela and G. Becher, Helv. Chim. Acta, 1999, 82, 16401655.

66 F. Seela and G. Becher, Chem. Commun., 1998, 2017-2018.

67 F. Seela and R. Kröschel, Nucleic Acids Res., 2003, 31, 71507158.

68 F. Seela and K. Xu, Org. Biomol. Chem., 2007, 5, 3034-3045.

69 M. Jeselnik, S. Jaksa and J. Kobe, ChemInform, 2004, 35, 153-160.

70 J. Wierzchowski, J. Sepioł, D. Sulikowski, B. Kierdaszuk and D. Shugar, J. Photochem. Photobiol., A, 2006, 179, 276-282.

71 F. Seela, A. M. Javelakar and I. Munster, Helv. Chim. Acta, 2005, 88, 751-765.

72 F. Seela, I. Munster, U. Loechner and H. Rosemeyer, Helv. Chim. Acta, 1998, 81, 1139-1155.

73 D. Jiang and F. Seela, J. Am. Chem. Soc., 2010, 132, 40164024.

74 H. U. Blank, I. Wempen and J. J. Fox, J. Org. Chem., 1970, 35, 1131-1138.

75 J. Wierzchowski, G. Mędza, J. Sepioł, M. Szabelski and D. Shugar, J. Photochem. Photobiol., A, 2012, 237, 64-70.

76 Z. Kazimierczuk and D. Shugar, Acta Biochim. Pol., 1973, 20, 395-402.

77 Z. Kazimierczuk, R. Mertens, W. Kawczynski and F. Seela, Helv. Chim. Acta, 1991, 74, 1742-1748.

78 S. A. Ingale, P. Leonard, Q. N. Tran and F. Seela, J. Org. Chem., 2015, 80, 3124-3138.
79 K. Ono, M. Ogasawara, Y. Iwata, H. Nakane, T. Fujii, K. Sawai and M. Saneyoshi, Biochem. Biophys. Res. Commun., 1986, 140, 498-507.

80 M. Cai, V. Sidorov, Y. F. Lam, R. A. Flowers and J. T. Davis, Org. Lett., 2000, 2, 1665-1668.

81 S. Kim, S. Lee, W. Sun, S. Oh and J. Kim, Arch. Pharmacal Res., 1999, 22, 619-623.

82 T. Davis, S. Tirumala, J. R. Jenssen, E. Radler and D. Fabris, J. Org. Chem., 1995, 60, 4167-4176.

83 W. Pfleiderer, Justus Liebigs Ann. Chem., 1961, 647, 167-173.

84 C. Roberts, R. Bandaru and C. Switzer, J. Am. Chem. Soc., 1997, 119, 4640-4649.

85 T. Golas, M. Fikus, Z. Kazimierczuk and D. Shugar, Eur. J. Biochem., 1976, 65, 183-192.

86 J. Sepiol, Z. Kazimierczuk and D. Shugar, Z. Naturforsch., C: Biosci., 1976, 31, 361-370.

87 R. Krishnamurthy, S. Pitsch, M. Minton, C. Miculka, N. Windhab and A. Eschenmoser, Angew. Chem., Int. Ed., 1996, 35, 1537-1541.

88 J. Hunziker, H. J. Roth, M. Böhringer, A. Giger, U. Diederichsen, M. Göbel, R. Krishnan, B. Jaun, C. Leumann and A. Eschenmoser, Helv. Chim. Acta, 1993, 76, 259-352.

89 A. Eschenmoser, Pure Appl. Chem., 1993, 65, 1179-1188.

90 A. Banerjee, W. Saenger, B. Lesyng, Z. Kazimierczuk and D. Shugar, Acta Crystallogr., Sect. B: Struct. Crystallogr. Cryst. Chem., 1978, 34, 2472-2477.

91 F. Seela, X. Peng and K. Xu, Nucleosides, Nucleotides Nucleic Acids, 2007, 26, 1569-1572.

92 Horiz. Biochem, ed. A. Rich, M. Kasha and B. Pullman, 1962, pp. 103-126.

93 A. P. Joseph, A. B. Steven, K. Tilman and E. M. Simon, Nature, 1990, 343, 33-37.

94 T. Horn, C.-A. Chang and M. L. Collins, Tetrahedron Lett., 1995, 36, 2033-2036.

95 C. Roberts, R. Bandaru and C. Switzer, Tetrahedron Lett., 1995, 36, 3601-3604.

96 A. Jaworski, J. S. Kwiatkowski and B. Lesyng, Int. J. Quantum Chem., 1985, 28, 209-216.

97 X. Chen, R. Kierzek and D. H. Turner, J. Am. Chem. Soc., 2001, 123, 1267-1274.

98 F. Seela, C. Wei, A. Melenewski and E. Feiling, Nucleosides Nucleotides, 1998, 17, 2045-2052.

99 A. Maciejewska, K. Lichota and J. Kusmierek, Biochem. J., 2003, 369, 611-618.

100 C. Switzer, S. Moroney and S. A. Benner, J. Am. Chem. Soc., 1989, 111, 8322-8323.

101 C. Y. Switzer, S. E. Moroney and S. A. Benner, Biochemistry, 1993, 32, 10489-10496.

102 Y. Tor and P. Dervan, J. Am. Chem. Soc., 1993, 115, 44614467.

103 H. Kamiya and H. Kasai, FEBS Lett., 1996, 391, 113-116.

104 J. Horlacher, M. Hottiger, V. N. Podust, U. Hübscher and S. A. Benner, Proc. Natl. Acad. Sci. U. S. A., 1995, 92, 63296333.

105 M. J. Lutz, H. A. Held, M. Hottiger, U. Hübscher and S. A. Benner, Nucleic Acids Res., 1996, 24, 1308-1313. 
106 M. J. Lutz, J. Horlacher and S. A. Benner, Bioorg. Med. Chem. Lett., 1998, 8, 499-504.

107 H. Kamiya and H. Kasai, Nucleic Acids Res., 2000, 28, 16401646.

108 H. Kamiya, H. Maki and H. Kasai, Biochemistry, 2000, 39, 9508-9513.

109 Y. Tsurudome, T. Hirano, H. Kamiya, R. Yamaguchi, S. Asami, H. Itoh and H. Kasai, Mutat. Res., 1998, 408, 121-127.

110 D. S. Hitchcock, A. A. Fedorov, E. V. Fedorov, L. J. Dangott, S. C. Almo and F. M. Raushel, Biochemistry, 2011, 50, 55555557.

111 T. Ohtsubo, K. Nishioka, Y. Imaiso, S. Iwai, H. Shimokawa, H. Oda, T. Fujiwara and Y. Nakabeppu, Nucleic Acids Res., 2015, 43, 3870-3871.

112 H. Kamiya and H. Kasai, J. Radiat. Res., 2000, 41, 349-354.

113 K. Fujikawa, H. Kamiya, H. Yakushiji, Y. Nakabeppu and H. Kasai, Nucleic Acids Res., 2001, 29, 449-454.

114 K. Fujikawa, H. Kamiya, H. Yakushiji, Y. Fujii, Y. Nakabeppu and H. Kasai, J. Biol. Chem., 1999, 274, 18201-18205.

115 J. C. Chaput and C. Switzer, Proc. Natl. Acad. Sci. U. S. A., 1999, 96, 10614-10619.

116 C. Switzer and J. C. Chaput, Methods, 2001, 23, 141-148.

117 P. Schuster, G. Zundel and C. Sandorfy, The Hydrogen Bond, North Holland Co., New York, 1976, p. 403.

118 G. A. Jeffrey and W. Saenger, Hydrogen Bonding in Biological Systems, Springer-Verlag, New York, 1991, pp. 103-110.

119 F. Seela, C. Wei and A. Melenewski, Origins Life Evol. Biospheres, 1997, 27, 597-608.

120 J. T. Davis and G. P. Spada, Chem. Soc. Rev., 2007, 36, 296313.

121 T. Giorgi, F. Grepioni, I. Manet, P. Mariani, S. Masiero, E. Mezzina, S. Pieraccini, L. Saturni, G. P. Spada and G. Gottarelli, Chem.-Eur. J., 2002, 8, 2143-2152.

122 J. T. Davis, Angew. Chem., Int. Ed., 2004, 43, 668-698.

123 T. J. Pinnavaia, C. L. Marshall, C. M. Mettler, C. L. Fisk, H. T. Miles and E. D. Becker, J. Am. Chem. Soc., 1978, 100, 3625-3627.

124 M. L. Meyer and J. Suhnel, J. Phys. Chem. A, 2003, 107, 10251031.

125 S. L. Forman, J. C. Fettinger, S. Pieraccini, G. Gottarelli and J. T. Davis, J. Am. Chem. Soc., 2000, 122, 4060-4067.

126 X. Shi, J. C. Fettinger and J. T. Davis, J. Am. Chem. Soc., 2001, 123, 6738-6739.

127 X. Shi, J. C. Fettinger and J. T. Davis, Angew. Chem., Int. Ed., 2001, 40, 2827-2831.

128 X. Shi, J. C. Fettinger and J. T. Davis, Angew. Chem., 2001, 2909-2913.

129 X. Shi, K. M. Mullaugh, J. C. Fettinger, Y. Jiang, S. A. Hofstadler and J. T. Davis, J. Am. Chem. Soc., 2003, 125, 10830-10841.

130 M. Cai, A. L. Marlow, J. C. Fettinger, D. Fabris, T. J. Haverlock, B. A. Moyer and J. T. Davis, Angew. Chem., Int. Ed., 2000, 39, 1283-1285.

131 A. L. Marlow and J. T. Davis, Tetrahedron Lett., 1999, 40, 3539-3542.
132 T. Evan-Salem, L. Frish, F. W. B. Van Leeuwen, D. N. Reinhoudt, W. Verboom, M. S. Kaucher, J. T. Davis and Y. Cohen, Chem.-Eur. J., 2007, 13, 1969-1977.

133 V. Abet, R. Evans, F. Guibbal, S. Caldarelli and R. Rodriguez, Angew. Chem., 2014, 126, 4962-4966.

134 M. Cai, X. Shi, V. Sidorov, D. Fabris, Y.-F. Lam and J. T. Davis, Tetrahedron, 2002, 58, 661-671.

135 E. H. Blackburn and J. W. Szostak, Annu. Rev. Biochem., 1984, 53, 163-194.

136 J. R. Williamson, M. K. Raghuraman and T. R. Cech, Cell, 1989, 59, 871-880.

137 F. Aboul-Ela, A. I. H. Murchie, D. G. Norman and D. M. J. Lilley, J. Mol. Biol., 1994, 243, 458-471.

138 A.-E. Fareed, I. H. M. Alastair and M. J. L. David, Nature, 1992, 360, 280-282.

139 W. Yong and D. J. Patel, Biochemistry, 1992, 31, 8112-8119.

140 F. Seela, C. Wei and A. Melenewski, Nucleic Acids Res., 1996, 24, 4940-4945.

141 C. Roberts, J. C. Chaput and C. Switzer, Chem. Biol., 1997, 4, 899-908.

142 E. A. Venczel and D. Sen, Biochemistry, 1993, 32, 6220-6228.

143 F. Seela and R. Kröschel, Bioconjugate Chem., 2001, 12, 1043-1050.

144 F. Seela and C. Wei, Chem. Commun., 1997, 1869-1870.

145 F. Seela, C. Wei, A. Melenewski, Y. He, R. Kröschel and E. Feiling, Nucleosides Nucleotides, 1999, 18, 1543-1548.

146 F. Seela and C. Wei, Helv. Chim. Acta, 1999, 82, 726-745.

147 N. B. Ramsing and T. M. Jovin, Nucleic Acids Res., 1988, 16, 6659-6676.

148 F. Seela, B. Gabler and Z. Kazimierczuk, Collect. Czech. Chem. Commun., 1993, 58, 170-173.

149 F. Seela, C. Wei and A. Melenewski, Nucleosides Nucleotides, 1997, 16, 1523-1527.

150 X.-L. Yang, H. Sugiyama, S. Ikeda, I. Saito and A. H. J. Wang, Biophys. J., 1998, 75, 1163-1171.

151 F. Seela, Y. He and C. Wei, Tetrahedron, 1999, 55, 94819500.

152 S. S. Pujari and F. Seela, J. Org. Chem., 2013, 78, 8545-8561.

153 N. M. Sangeetha and U. Maitra, Chem. Soc. Rev., 2005, 34, 821-836.

154 I. Bang, Biochem. Z., 1910, 26, 293-311.

155 H. Zhao, A. H. Schäfer and F. Seela, ChemPlusChem, 2017, 82, 826-833.

156 H. Zhao, D. Jiang, A. H. Schäfer and F. Seela, ChemPlusChem, 2017, 82, 778-784.

157 M. Guvendiren, H. D. Lu and J. A. Burdick, Soft Matter, 2011, 8, 260-272.

158 A. Biswas, S. Malferrari, D. M. Kalaskar and A. K. Das, Chem. Commun., 2018, 54, 1778-1781.

159 F. Tang, H. Feng, Y. Du, Y. Xiao, H. Dan, H. Zhao and Q. Chen, Chem.-Asian J., 2018, 13, 1962-1971.

160 B. Adhikari, A. Shah and H.-B. Kraatz, J. Mater. Chem. B, 2014, 2, 4802-4810.

161 J. Kim, S. Lee, Y. Han, J. Moon and J. Kim, Arch. Pharmacal Res., 1994, 17, 115-118.

162 V. Venkatesh, N. K. Mishra, I. Romero-Canelon, R. R. Vernooij, H. Shi, J. P. C. Coverdale, 
A. Habtemariam, S. Verma and P. J. Sadler, J. Am. Chem. Soc., 2017, 139, 5656-5659.

163 H. Zhao, H. Feng, J. Liu, F. Tang, Y. Du, N. Ji, L. Xie, X. Zhao, Z. Wang and Q. Chen, Biomaterials, 2019, 230, DOI: 10.1016/j.biomaterials.2019.119598.

164 M. M. Cox, Mutat. Res., 1997, 384, 15-22.

165 H. Kamiya and H. Kasai, Biochemistry, 1997, 36, 1112511130.

166 M. Inoue, H. Kamiya, K. Fujikawa, Y. Ootsuyama, N. Murata-Kamiya, T. Osaki, K. Yasumoto and H. Kasai, J. Biol. Chem., 1998, 273, 11069-11074.

167 S. C. Johnson, C. B. Sherrill, D. J. Marshall, M. J. Moser and J. R. Prudent, Nucleic Acids Res., 2004, 32, 1937-1941.

168 S. C. Johnson, D. J. Marshall, G. Harms, C. M. Miller, C. B. Sherrill, E. L. Beaty, S. A. Lederer, E. B. Roesch, G. Madsen, G. L. Hoffman, R. H. Laessig, G. J. Kopish, M. W. Baker, S. A. Benner, P. M. Farrell and J. R. Prudent, Clin. Chem., 2004, 50, 2019-2027.

169 J. D. Bain, S. Christopher, C. Richard and A. B. Steven, Nature, 1992, 356, 537-539.

170 F. Seela, D. Jiang and S. Budow, ChemBioChem, 2010, 11, 1443-1450.

171 F. A. Fuhrman and G. J. Fuhrman, Comp. Biochem. Physiol., C: Comp. Pharmacol., 1982, 72, 203-210.

172 P. L. Ewing, F. Schlenk and G. A. Emerson, J. Pharmacol. Exp. Ther., 1949, 97, 379-383.

173 D. A. Clarke, J. Davoll, F. S. Philips and G. B. Brown, J. Pharmacol. Exp. Ther., 1952, 106, 291-302.

174 K. Weronika, C. Tomasz and P. Anna, PLoS One, 2018, 13, e0197835.

175 F. A. Fuhrman, G. J. Fuhrman, Y. H. Kim, L. A. Pavelka and H. S. Mosher, Science, 1980, 207, 193-195.

176 P. Buckle and I. Spence, Naunyn-Schmiedeberg's Arch. Pharmacol., 1981, 316, 64-68.

177 J. F. Marwood, Clin. Exp. Pharmacol. Physiol., 1981, 8, 575584.

178 D. Jamieson and P. Davis, Eur. J. Pharmacol., 1980, 67, 295300.

179 M. Radulovacki, R. M. Virus, D. Rapoza and R. C. Crane, Neuropharmacology, 1985, 24, 547-549.
180 P. Buckle and I. Spence, Naunyn-Schmiedeberg's Arch. Pharmacol., 1982, 319, 130-135.

181 M. Huang, H. Shimizu and J. W. Daly, J. Med. Chem., 1972, 15, 462-466.

182 L. P. Davies, K. M. Taylor, R. P. Gregson and R. J. Quinn, Life Sci., 1980, 26, 1079-1088.

183 L. P. Davies, J. Baird-Lambert and J. G. Hall, Neuropharmacology, 1987, 26, 493-497.

184 W. J. McDowell and G. N. Case, Anal. Chem., 1992, 64, 30133017.

185 J. C. Bryan, K. Kavallieratos and R. A. Sachleben, Inorg. Chem., 2000, 39, 1568-1572.

186 J. C. Bryan, R. A. Sachleben and B. P. Hay, Inorg. Chim. Acta, 1999, 290, 86-94.

187 Y. Deng, R. A. Sachleben and B. A. Moyer, J. Chem. Soc., Faraday Trans., 1995, 91, 4215-4222.

188 R. A. Sachleben, Y. Deng, D. R. Bailey and B. A. Moyer, Solvent Extr. Ion Exch., 1996, 14, 995-1015.

189 J. T. Davis, S. K. Tirumala and A. L. Marlow, J. Am. Chem. Soc., 1997, 119, 5271-5272.

190 A. Casnati, A. Pochini, R. Ungaro, F. Ugozzoli, F. Arnaud, S. Fanni, M.-J. Schwing, R. J. M. Egberink, F. d. Jong and D. N. Reinhoudt, J. Am. Chem. Soc., 1995, 117, 2767.

191 S. Lee, J. Lamb, M. Cai and J. Davis, J. Inclusion Phenom. Macrocyclic Chem., 2001, 40, 51-57.

192 F. W. B. van Leeuwen, W. Verboom, X. Shi, J. T. Davis and D. N. Reinhoudt, J. Am. Chem. Soc., 2004, 126, 16575-16581.

193 F. W. B. van Leeuwen, C. J. H. Miermans, H. Beijleveld,

T. Tomasberger, J. T. Davis, J. T. Davis, W. Verboom and D. Reinhoudt, Environ. Sci. Technol., 2005, 39, 5455-5459.

194 S. Lee, J. Kim, S. Lee and J. Kim, Arch. Pharmacal Res., 1995, 18, 138-139.

195 R. Nowak, M. Sawardo-Rochowska, Z. Kazimierczuk and R. J. Nowak, Eksperimental'naia Onkologiia, 2004, 26, 20-23. 196 C. Hagen, Biochim. Biophys. Acta, 1973, 293, 105-110.

197 J. Doskocil and A. Holý, Nucleic Acids Res., 1974, 1, 645-652.

198 J. H. Wissler, S. Kiesewetter, E. Logemann, M. Sprinzl and L. M. G. Hellmeyer Jr, Biol. Chem., 1988, 369, 948-949. 